IZA DP No. 9225

Understanding the Effects of Education on Health: Evidence from China

Wei Huang

July 2015 


\title{
Understanding the Effects of Education on Health: Evidence from China
}

\author{
Wei Huang \\ Harvard University \\ and IZA
}
Discussion Paper No. 9225
July 2015

IZA

P.O. Box 7240

53072 Bonn

Germany

\author{
Phone: +49-228-3894-0 \\ Fax: +49-228-3894-180 \\ E-mail: iza@iza.org
}

\begin{abstract}
Any opinions expressed here are those of the author(s) and not those of IZA. Research published in this series may include views on policy, but the institute itself takes no institutional policy positions. The IZA research network is committed to the IZA Guiding Principles of Research Integrity.

The Institute for the Study of Labor (IZA) in Bonn is a local and virtual international research center and a place of communication between science, politics and business. IZA is an independent nonprofit organization supported by Deutsche Post Foundation. The center is associated with the University of Bonn and offers a stimulating research environment through its international network, workshops and conferences, data service, project support, research visits and doctoral program. IZA engages in (i) original and internationally competitive research in all fields of labor economics, (ii) development of policy concepts, and (iii) dissemination of research results and concepts to the interested public.
\end{abstract}

IZA Discussion Papers often represent preliminary work and are circulated to encourage discussion. Citation of such a paper should account for its provisional character. A revised version may be available directly from the author. 


\section{ABSTRACT}

\section{Understanding the Effects of Education on Health: Evidence from China*}

Using a national representative sample in China from three largest on-going surveys, this study examines the effects of education on health among working-age population and explores the potential mechanisms. Using the exogenous variation in temporal and geographical impacts of Compulsory Schooling Laws (CSLS), it finds an additional year of schooling decreases 2-percentage points in reporting fair or poor health, 1-percentage points for underweight and 1.5-percentage points for smoking, and increases cognition by about 0.16 standard deviation. Further analysis also suggests that nutrition, income, cognition and peer effects are important channels in the education-health nexus, and all of these factors explain almost half of the education's impact. These suggest that CSLs have improved national health significantly in China and the findings help to explain the mixed findings in the literature.

JEL Classification: $\quad$ I12, I21, I28

Keywords: education, health, China

Corresponding author:

Wei Huang

Department of Economics

Harvard University

1805 Cambridge Street

Cambridge, MA 02138

USA

E-mail: weihuang@fas.harvard.edu

\footnotetext{
* I thank Raj Chetty, David Cutler, Richard Freeman, Edward Glaeser, Lawrence Katz and Adriana Lleras-Muney for their constructive comments and suggestions. I also thank the participants of Harvard China Seminar, Harvard Labor Lunch, North America China Economic Society Meeting and Seminars in Chinese Academy of Social Sciences, China Center for Economic Research and East China Normal University for their helpful suggestions. I am also grateful for the financial support from the Cheng Yan Family Research Grant from Department of Economics at Harvard and Jeanne Block Memorial Fun Award from IQSS. All errors are mine.
} 


\section{Introduction}

The large and persistent relationship between education and health has been well established, which has been observed in many countries and time periods, and for a wider variety of health measures. ${ }^{1}$ The causal effects of education on health are of central interests among the economists: they are crucial to models of the demand for health capital (Grossman 1972) and the models of the influence of childhood development on adult outcomes (Heckman 2007; Heckman 2010; Conti, Heckman, and Urzua 2010). Moreover, establishing whether and to what extent that education causally impacts on health are essential to the formation and evaluation of education and health policies. If the health effects of education are large enough, education policies would be powerful tools for improving national health (Lleras-Muney 2005; Clark and Royer 2013). This is meaningful especially in comparison to high cost of access to healthcare insurance or additional health care spending with the uncertain or little return in both developed and developing countries all over the world (Chen and Jin 2012; Filmer and Prichett 1997; Lei and Lin, 2009; Newhause 1993; Weinstein and Skinner 2010).

Although many empirical studies have investigated the causality between education and health outcomes across different countries in different periods, the findings are mixed. The conflicting findings even appear when using the similar identification strategy based on the exogenous variations in timing of Compulsory School Laws (CSLs). For example, Lleras-Muney

\footnotetext{
1 These relationships have been extensively documented. For mortality in the US see Kitagawa and Hauser (1973), Christenson and Johnson (1995), Deaton and Paxson (2001), and Elo and Preston (1996); for risk factors see Berger and Leigh (1988), Sobal and Stunkard (1989), Adler et al (1994); for diseases morbidity see Pincus, Callahan and Burkhauser (1987); for health behaviors see Sander (1995), Kenkel (1991), Meara (2001), de Walque (2007), Leigh and Dhir (1997), Gilman (2007), Kemptner et al. (2011), Jurges at al. (2011), Park and Kang (2008), and Braakmann et al. (2011), Li and Powdthavee (2014). Several review papers also report these associations; see for example Grossman (2006), Cutler and Lleras-Muney (2006) and Oreopoulos and Salvanes (2011).

The relationship is so ubiquitous that is often simply referred as "the gradient" (Deaton 2003) and substantial attention has been paid to these "health inequalities". Gradients in health by education are now being systematically monitored in many countries like the US and UK.
} 
(2005) used state-level changes in CSLs from 1915 to 1939 in the United States as instruments for education and identified the effects of education on mortality are larger than the partial correlation. But Clark and Royer (2013) used two education policy reforms in the UK but found no impact on mortality. ${ }^{2}$ Some mixed findings are even found within the same country, ${ }^{3}$ and the debate on the causal effects of education is still going on (Stephens and Yang, 2014).

The differential findings in the literature call for the studies to investigate the mechanisms in the education-health nexus. Unfortunately, little empirical evidence for potential mechanisms has been provided yet largely due to data limitation. The CSLs changes in industrial countries usually happened in earlier times and the affected cohorts have been really old when surveys were took place: CSLs changes used in Lleras-Muney (2005) happened between 1914 and 1939 and those happened in Germany between 1949 and 1969, while the surveys used in the analysis were conducted in late $20^{\text {th }}$ century.

But some pathways are well known by economists though lack of solid evidence. For example, education may improve the health status later on via increasing the cognition and knowledge level and so that the individuals will understand how to take care of themselves in better way: they are able to recognize the health information on the food labels and follow the instructions from the doctors better. For another, as an important predictor for lifetime permanent income, individuals with higher education are able to purchase food of higher quality and live in the houses/apartments with better conditions. The impact of education may also be amplified by peer effects: those with lower education may start to develop bad health behaviors due to there

\footnotetext{
2 In addition, effect on mortality has also been found in the Netherlands (van Kippersluis et al. 2011) and Germany (Kemptner et al. 2011) but not in France (Albouy and Lequien, 2009) or Swedes (Lager and Torssander 2012).

3 For the UK, Silles (2009) found more schooling lead to better self-reported health and fewer life-activity limitations but Clark and Royer (2013) found no impact on mortality. For the US, Lleras-Muney (2005) identified a large effect but Fletcher (2014) revisited the case and did not find evidence for causality on mortality. Some recent literatures have documented the heterogeneous effects across different countries, e.g. Cutler and Lleras-Muney (2012), Cutler et al. (2014) and Gathmann et al. (2014).
} 
being more peers around smoking or drinking heavily and they are more likely to suffer depression if more peers are in the low mood.

Using a national representative sample from three large individual level datasets in China and exploiting the temporal and geographical variations in CSLs change in around 1986 across the provinces, this paper constructs instruments for education, then finds causal effects of education (increased by the CSLs) on health and further investigate the possible channels. The CSLs in China was formalized by the central government in the 1986, which are usually named by "9-year" CSLs because it requires all the age-eligible children to have at least nine-year education (i.e. primary school and junior middle high school). This is the first time for the largest development country to implement the national education policy and it got great achievements: the enrollment rate for junior high school increased by 26 percentage points from $69.5 \%$ in 1986 to $95.5 \%$ in 2000 , and the number of students enrolled in junior high school increased by 8.9 million.

The analysis uses two sources of variation. First, following previous literature, I exploit the plausibly exogenous time variation in the timing of the CSLs adoption in different provinces. Although the central government initiated the CSLs in 1986, it allowed the provincial government to implement in different times. But the variation in timing is small; the difference between the earliest province and the latest one is only 5 years. This study finds the second variation source: the cross-sectional variation in the education's potential increase across the provinces. Following the requirement by the central government, all the local provinces require 9-year compulsory schooling, even in the provinces with very low education prior to the CSLs. The provinces with lower education prior to the laws will potentially increase more in education after the implement of CSLs. Hence, I measure the potential increase in education as the proportion of ones with fewer than 9 years education among those who are ineligible for the CSLs in the local province. Using the two sources of variation together, I construct the interaction of the timing of CSLs implementation and the potential education increase in local 
province and use this as an additional instrument for the individual education. The baseline estimates, which examine the sample combined from three on-going surveys, include province and birth cohort fixed effects that control for time-invariant differences across different provinces and differences across different birth cohorts, respectively. The baseline estimates also include sample source fixed effects and province-specific year fixed effects as well as their interactions to control for changes over time that may affect provinces in different data sources.

The strategy follows the similar logic as a difference-in-differences (DID) estimator. The coefficient on the interaction captures the difference in years of schooling among those eligible to CSLs to those ineligible to CSLs in the provinces with potentially larger increase in education relative to provinces with potentially smaller increase in education. There are several potential concerns over the excludability of the instruments. First, the estimation shares the similar concern as other DID estimation: different time trends across the regions caused by other factors like economic growth may drive the estimation. To shed light on this, I further control for province-specific birth cohort linear trends, and find little change in the point estimates as well as the significance. Second, China is a country with many reforms in government policies during the period examined and thus it is possible that the timing of CSLs and the interaction may pick up the variations of other policies. Noting that the CSLs in China is "9-year" compulsory schooling, I directly test it by showing that CSLs measures in this study increase the years of schooling up and only up to 9 years. Third, the main finding in the first stage regressions is that those provinces with lower education potentially increase more after the CSLs, and it is possible this is just "regression to the mean" rather than the effects of the policy. I conduct a placebo test in this study with assumption that the CSLs happened five years before and find there is no evidence for the "regression to the mean" existing before the actual CSLs implementation. Fourth, it is possible that the regions with lower education prior to CSLs are also the ones with poorer nutrition in the beginning, and the more increase in education in these regions may just imply larger nutrition improvement which will then be correlated with health in the future. I shed 
light on this issue by showing the effects of CSLs on height, a measure for younger adulthood nutrition status, and find no evidence for the correlation of the measures of CSLs with it.

Our main health outcomes are indicators for self-reported fair or poor health, underweight or Body Mass Index (BMI), smoking and two continuous variables measuring the cognition. Both reduced form estimation and the Two-Stage Least-Squares (2SLS) estimation yield pronounced effects of education on these health outcomes. The results show that one additional year in schooling improves health of the population by reducing reported fair or poor health rate by 2 percentage points, especially for women. An additional year in schooling also leads to lower poor nutrition rate (i.e. 1.2 percentage points) and lower smoking rate (i.e. 1.5 percentage points), respectively. This study also examined the causal effects of education on cognition measured by words recall and mathematical calculation, which is the first evidence in literature showing the effects in the working-group people. ${ }^{4}$ These results are also robust to different model specifications.

To better understand how education can affect health, I provide additional results about the potential mechanisms how education affects health. Following the framework in Cutler and Lleras-Muney (2010), I find that nutrition (measured by BMI), income, and cognition explain the impact of education on self-reported health by $11-13 \%, 15-22 \%$ and $13 \%$, separately. Suggestive evidence shows that peer effects can explain 10-18\% percent of the impact. These factors together can explain up to $45 \%$ of the effects of education. Smoking behaviors seems to be unrelated in the nexus between education and self-reported health. The findings here suggest that

\footnotetext{
${ }^{4}$ The importance of this relationship is emphasized by the growing literature in development economics on cognitive abilities. Hanushek and Woessmann (2008) mentioned that education would not enhance the economy without increasing the cognitive abilities. But no study provides empirical evidence on causality among working-age group though associations have been established. There are some studies to investigate the casual impact of education on cognition, but mainly for those aged people, like Glymour et al. (2008) for the US, Banks and Mazzonna (2012) for the UK and Huang and Zhou (2013) for China. In addition, we examine cognition because Cognitive ability also plays an important role in developing good health behaviors (Cutler and Lleras-Muney 2010).
} 
the pathways that education impacts health may be not single-factored since it cannot be simply explained by income or nutrition or other factor examined here. This is consistent with the conflicting findings in the literature. For example, it is reasonable that Clark and Royer (2013) found that education increase income but not health because the proportion of the causality explained by income is about one fifth.

Our findings contribute to several literatures. First, this paper contributes to the famous debate between Grossman and Fuchs (Grossman, 2004), by providing support for the effectiveness of education policies in improving education and health status and establishing the causal relationship among the working-age population in China. Using the most recent education reform polices with remarkable achievements in the largest developing country, this paper builds up the literature by studying causality between education and health under the developing country and working-age population setting, because what the literature examined is mainly for developed countries and for people at older age. This study also fills in the gap in the literature by examining the potential mechanisms why the education's effects on health for the first time, including cognition, nutrition, peer effect and income, which helps to explain the large heterogeneity in impact of education on health across different nations and periods.

The findings also contribute to the causality from education to BMI under a developing country setting. Contrary to the results in previous literature like Brunello et al. (2013) which found a large and negative effect of education on BMI, the results in this paper suggest that education increases BMI. The reason may be that, as found in the later sections, the underweight is a more serious health problem in the developing country like China compared to obesity. The findings highlight the different estimates under different settings between developed and developing countries but suggest the same conclusion that education improves health status.

In addition, the results also contribute to the growing literature in development about the importance of cognition. For example, Hanushek and Woessmann (2008) mentioned that the impact of education on economic growth is mainly through the pathway of cognition, and 
Hanushek (2013) also found that improvements in long run growth are closely related to the level of cognitive skills of the population. Due to education policies took place much earlier than our realization about the importance of cognition, the evidence for causal effect of education on cognition is rare in literature, especially for the working-age population. ${ }^{5}$ The findings in this paper fill in the gap.

\section{Background and Data}

As emphasized in previous literature, the OLS coefficients cannot be interpreted as causality with education as key independent variable and health outcomes as dependent one due to endogeniety, which may originate from many aspects, including family background, unobservable inherent ability, habit and personality like patience, and even the reversal causality that those with longer life expectancy will invest more in education (Jayachandran and Lleras-Muney 2009). Researchers investigating the causality have been insistently searching for exogenous variations in education by public policies or laws (e.g. Lleras-Muney 2005).

One of the most widely used strategies is to construct instrumental variables based on the Compulsory schooling laws (CSLs) to derive the causal impact of education. Following this strand of literature, this paper explores the variations from the CSLs changes in different provinces and different time in China and then uses the exogenous variations to derive the causal effects of education.

\subsection{Compulsory Schooling Laws in China}

China's Compulsory Education Laws were passed on April 12, 1986 and officially went into effect on July 1, 1986. This was the first time that China used a formal law to specify educational policies for the entire country. This law had several important features (China Ministry of

\footnotetext{
5 Some studies investigated the casual impact of education on cognition but mainly for those aged people, like Glymour et al. (2008) for the US, Banks and Mazzonna (2012) for the UK and Huang and Zhou (2013) for China.
} 
Education 1986): 1) 9 years of education became compulsory; 2) children were generally supposed to start their compulsory education at 6 years of age in principle, 3) compulsory education was free of charge; 4) it became unlawful to employ children who are in their compulsory schooling years and 5) local governments were allowed to collect education taxes to finance compulsory education (Fang et al. 2013). Different from the US and European countries increasing one or two years in the compulsory schooling years, the laws in China actually use the uniform "9 years" for the length of years of compulsory schooling no matter where it is.

Local provinces were also allowed to have different effective dates for implementing the law because the central authorities recognized that not all provinces would be ready to enforce the law immediately (Fang et al. 2013). Table A2 reports the different timing for the CSLs in the provinces covered in the sample as well as the first cohort affected. The variation in the timing is not large because most of the provinces started in 1986 or 1987, and the year gap between the earliest provinces and latest province in the sample is 5 years. ${ }^{6}$

The central government also planed to have different implement forces across different regions. As pointed out in a document "Decisions about the Education System Reform" in 1985, the central government divided the whole nation into three categories: 1) cities and developed regions (cities and some towns); 2) middle-level developed regions (like most of the towns and part of the villages); and 3) least-developed regions (mainly villages). And the central government also decided to the mainly support the less-developed regions: as the document said, "the nation will try best to support the less-developed regions to reduce the illiterate rate". One direct consequence is that the CSLs have compressed the inequality of the education across the nation and narrowed the education gap between urban and rural areas. For example, the illiterate

\footnotetext{
6 The timing of the CSLs, as shown in Table A2, is weakly correlated with the education level of each province (Correlation coefficient $=0.2$ ). Regressing the law effective year on the education prior to CSLs yield insignificant ( $\mathrm{p}$-value $=0.27)$ though positive coefficient. In further analysis, this study also allows the provinces to endogenously determine when to start the CSLs, finding the results are also consistent. Results are available upon request.
} 
rate for those aged over 15 in rural areas declined by 25 percentage points from $37.7 \%$ in 1982 to $11.6 \%$ in 2000 while that in urban areas only declined by 12 percentage points from $17.6 \%$ to $5.2 \%$ in the same period (Yearbooks Population Survey, 1982 and 2000).

The CSLs in China got great achievements: the enrollment rate for junior high school increased by 26 percentage points from $69.5 \%$ in 1986 to $95.5 \%$ in 2000, and the number of students enrolled in junior high school increased by 8.9 million, which made China the first and the only country attaining the "nine-year compulsory schooling" goal among the nine largest developing countries. ${ }^{7}$

Since it is the first time that China started to have such laws, the age-eligible children are defined as those aged between 6 and 15. Therefore, those aged 12, for example, are required to go to school to receive education until they are reach 16. But afterwards, they can stop their education and go to work because they are not age-eligible any more. Thus, the laws actually required the minimum school leaving age being 16 rather than truly "9-year" formal education, at least in the first few years.

\subsection{Data and Variables}

The main sample used in this study is from CFPS, CHIPS and CHNS, three on-going and largest surveys in China. The detailed description is in Data Appendix. I keep the variables consistently measured across the datasets: 1) demographic variables, including gender, year of birth, hukou province (i.e. the province where the household was registered), and type of hukou (i.e. Agriculture and non-agriculture); 2) socioeconomic variables like years of education and marital status; 3) health and health behavior variables like self-reported health, smoking status, BMI, and cognition. The survey year in the sample I used spanned from 1995 to 2011. Because the compulsory schooling laws was announced and implemented in 1986 and local provinces may start it a little earlier or later, I keep those birth cohorts born after 1955 and earlier than 1993

\footnotetext{
7 The nine countries are China, India, Indonesia, Pakistan, Bangladesh, Mexico, Brazil, Egypt and Nigeria.
} 
so that there are many affected and unaffected cohorts in all the datasets. Furthermore, I also restrict the sample to the individuals aged over 18 because most of the respondents have completed their education by age 18. For simplicity, I also drop those aged over 50 because the population starts to quit the labor force and the mortality rate start to increase at that age. The total number of observations is over 100 thousand, which is the largest micro-level Chinese sample so far. Because of different questionnaires used in each survey, I searched across the different datasets to collect the consistent measures for health outcomes, including self-reported health, smoking, BMI, and cognition.

\section{Self-Report Health}

Our measure of self-reported health is based on the question "How is your health in general?" in the three survey, for which the answers are (1) Excellent, (2) very good, (3) good, (4) fair and, (5) poor. $^{8}$ Indicator for reported fair or poor health is equal to one if the answer is 4 or 5 , and zero otherwise. Although individual mortality is a more accurate and objective measure for health and has been widely used in previous literature, it is not collected by the surveys used in this study. Also note that the sample here is much younger than those examined in previous literature, and the mortality rate for this age group is too low. But previous literature suggests the self-reported health is highly predictive of mortality and other objective measures of health (Idler and Benyamini, 1997; Idler and Benyamini 1997; Kawada 2014), and thus this study use this measure as a major outcome for individual health outcome. The mean values and standard deviations are reported in Appendix Table A1. There is about 19 percent of the sample reporting poor health and 30 percent reporting excellent health.

\section{[Table A1 about here]}

\footnotetext{
8 But the measure in CHNS is four-point one, which is (1) very good, (2) good, (3) fair and (4) poor. I consistently match the answer to the other datasets. In the analysis, I include saturated fixed effects for province, calendar year and surveys as well as all the three interactions. Furthermore, I also conduct a series of robustness checks, including dropping the CHNS data and using reported excellent health, which yields very consistent results.
} 


\section{$\underline{B M I, \text { Underweight and Obesity }}$}

BMI is also a widely used variable in the literature to descript the situation of nutrition and has shown to be correlated with mortality and economic growth (Rolland-Cachera et al. 1991; Fogel 1994; Naidu et al. 1994). The three surveys all provide information in height and weight, and I calculate BMI based on these measures. ${ }^{9}$ I also set those BMI less than 10 or larger than 50 (less than 1 percent of the sample) as missing because these outliers are mostly due to falsely reporting. Underweight is defined as BMI less than 18.5 and obesity is equal to one for those with a BMI greater than 30. Contrary to the popular obesity in the developed areas like the US and Europe, the obesity problem seems not to be a big issue. Table A1 tells us the obesity rate in the young adults in China is only 2 percent. Compared to obesity, underweight is a more salient problem, with about 8 percent people with BMI smaller than 18.5. And there are 12 percent of women in the sample suffering underweight, though not reported in this table.

\section{$\underline{\text { Smoking }}$}

Due to high smoking rate in China, large expenditure and potential huge burden on health in the future (US Department of Health and Human Services 2014) and the close relationship between smoking and mortality, this study also examines the relationship between smoking and education. In many of the surveys, respondents were asked "Do you smoke now?" or "Did you ever smoke last week?"10 If the answer to these questions is "yes", I then code the respondents as current smokers, which equals to one if they are, and zero if otherwise. Table A1 tells us that the smoking rate, 26 percent, is really high. Actually, this statistic is mostly driven by male sample, whereas the smoking rate is higher than 50 percent, almost three times of that in the US

\footnotetext{
${ }^{9}$ Height and weight are reported by respondents themselves in CHIPS and CFPS but are measured by professional nurses in CHNS. This study simply takes the BMI derived from the reported variables and that from measured variables equally. In our regressions, we controlled for the indicators for calendar year, data source and hukou provinces and all of their interactions to capture any possible systematic bias.

${ }^{10}$ The way to ask the question is a bit different in different questionnaires. I did not differentiate them in this study. Unfortunately, the surveys did not provide consistent measure for drinking and other health behaviors.
} 
(US Department of Health and Human Services 2014).

\section{Cognitive abilities}

Cognition, an important measure of mental health, refers to mental processes that involve several dimensions, including thinking part of cognition and includes memory, abstract reasoning and executive function, and the knowing part, which is the accumulation of influence from education and experience. (McArdle, et al., 2002; Smith et al. 2014).

In the CFPS questionnaire, there is a section to test respondents' cognitive functioning. The cognitive abilities are measure by two sets of tests. For the words recalling test, interviewers read a list of ten nouns, and respondents were asked immediately to recall as many of the nouns as they could in any order. The test would stop if the respondents continuously spoke three nouns that were not in the list. The other test is about mathematical calculation ability. In this test, the respondents were asked to answer the 8 or 10 questions about math, ${ }^{11}$ like how many you will get when subtract 10 by 3 . This test would also terminate if the respondents answer three questions wrongly continuously. Based on the test procedure, I calculate the proportion of right answers of each test for each individual who participated as the measure for cognition. ${ }^{12}$ Because of different number of questions are used in the different survey years, I calculated the Z-score for the cognition measures in each year and used them as my dependent variables. Therefore, the mean and standard deviations are zero and one as set.

\section{$\underline{\text { Demographics and Education }}$}

The basic demographic variables like education, gender, type of hukou (urban/rural), and year of birth (or age) are consistently collected in the surveys. For all the surveys, information about years of education is provided. I use this variable directly. ${ }^{13}$ The basic statistics are also

\footnotetext{
11 The number of questions required to answer is different in the two years they covered.

12 There is sizeable proportion of people refused to give responses in mathematical calculation section.

13 There are some people reporting over even 25 years of schooling and I drop the 10 observations in my sample. I also use a dummy variable indicating whether the individual has at least 9 years of education as a robustness check.
} 
reported in the panel B of Table A1. Those in the sample are aged 30 on average, 33 percent of them lived in urban areas, and half of them are women.

\section{First Stage: Impact of CSLs on Education}

\subsection{Graphic analysis}

The feature of CSLs in China, as mentioned above, is the length of compulsory schooling is 9 years no matter what the education level was prior to the policy change. I hypothesize that the provinces with lower education just prior to the CSLs would increase more in education due to the uniform 9-year threshold. To verify it, I first calculate the proportion of those with fewer than 9 years education in the birth cohorts prior to the CSLs (within 15 years) in each province and report them in Table A2. This variable varies much across the provinces, from 0.05 for Beijing to 0.79 for Fujian.

\section{[Table A2 about here]}

To illustrate the idea clearly, I use graphic analysis to shed light on it. First, I divide the provinces by the median level of proportion of individuals with less than 9-year education prior to CSLs. Then for each subsample, I estimate how the years of schooling change across different birth cohorts relative to the CSLs eligibility, with controlling for gender indicator and dummies for hukou province, survey year, sample source (CHNS/CFPS/CHIPS) and all of their interactions. The reference group for each subsample, the reference group is the cohort just eligible for the CSLs (i.e. the birth cohorts aged 15 when CSLs started in the local province). For each subsample, Figure 1 reports the OLS point estimation and confidential intervals for the coefficients on the indicators of the relative years to the CSLs eligibility. Consistent with the hypothesis, the education in the individuals in the provinces with lower education before CSLs (the blue line) increases more afterwards: years of schooling in the regions with lower education prior to the CSLs increased about 1.5 years while that in the regions with relative higher 
education before CSLs only increased about 0.8 years.

[Figure 1 about here]

\subsection{First Stage: Methodology and Results}

The above preliminary graphic analysis provides evidence for the hypothesis and I estimate the following equation to further test the hypothesis:

(1) Edu $_{i}=\alpha_{0}+\alpha_{1}$ Eligible $_{i j}+\alpha_{2}$ prop $_{j}^{\text {prior }<9} \times$ Eligible $_{i j}+\alpha X_{i}+\delta_{s j t}+\epsilon_{i}$

In which the dependent variable $E d u_{i}$ denotes year of schooling of individual $i$, and Eligible $_{i j}$ denotes to what extent that individual $i$ in province $j$ is eligible for the compulsory schooling laws, which equals to one if the individual is fully eligible to the CSLs (i.e. aged 6 or below) and equals to zero if the individual is ineligible (i.e. aged 16 or above). Then I assume the eligibility follows the linear function in between, as Figure 2 shows. ${ }^{14}$

[Figure 2 about here]

One potential issue here is that the hukou province may be not the province where they received their education. It is true but I cannot address this issue without further information since the surveys do not provide needed information. But according to the census 2005 and later waves of CHNS, the proportion for those with the province living in being not the hukou province is less than 5 percent, suggesting this may not the first order issue driving the results.

In equation (1), $X_{i}$ denotes a set of control variables, including dummies for gender, type of hukou (urban/rural), married, age and year of birth. $\delta_{s j t}$ denotes a set of dummies, including sample $s$ which individual $i$ is from, province $j$ where individual $i$ is now living and survey year $t$ when $i$ was interviewed and all of their interactions. Adding $\delta_{s j t}$ into the equation does not only control for the potential systematic difference existing across datasets but also control for the

\footnotetext{
14 The results do not rely on the linear function assumption. I also used the step function in between (i.e. every three years or five years) and find consistent results, which are available upon request.
} 
different conditions or trends of the provinces within the survey year span period.

prop ${ }_{j}^{\text {prior }<9}$ denotes the proportion of people with fewer than 9 years schooling in the population born prior to the CSLs (bandwidth $=15$ years) in province $j$ (i.e. the statistics in the last column reported in Table A2). Main effects of prop ${ }_{j}^{\text {prior }<9}$ have been absorbed by the province dummies in $\delta_{s j t}$. The coefficients of eligibility $\left(\alpha_{1}\right)$ and the interaction $\left(\alpha_{2}\right)$ are of main interest because it captures the main effect of CSLs and different extents of increase of years of education after the CSLs between the provinces with lower and higher prior education.

The strategy above follows the similar logic as a DID estimator. In actual regressions, the interaction is between the CSLs eligibility and the demeaned value of the proportion of individuals with less than 9-year education in the local province. Thus the coefficient on eligibility $\left(\alpha_{1}\right)$ can be interpreted as the impact of CSLs on education at the mean level of prior education. $\alpha_{1}>0$ is expected because it means that the CSLs increased education. The coefficient on the interaction $\left(\alpha_{2}\right)$ captures the difference in years of schooling among those eligible to CSLs to those ineligible to CSLs in the provinces with potentially larger increase in education relative to provinces with potentially smaller increase in education. If $\alpha_{2}>0$, then it means those with lower education prior to CSLs will increase more afterwards.

Table 1 reports the OLS estimation for $\alpha_{1}$ and $\alpha_{2}$, with the standard errors clustered at provincial-year of birth level. Column 1 presents the results without the interaction term, showing that CSLs increase the years of schooling by 1.2 years on average, which is also consistent with the magnitude shown in Figure 1. Estimates in column 2 show that $\alpha_{1}>0$ and $\alpha_{2}>0$, with joint F-test statistics rejecting the hull hypothesis. The impact of CSLs at the mean level of prior education $\left(\alpha_{1}\right)$ is consistent with the estimates in column 1 . The estimated $\alpha_{2}$ is also significantly positive. The magnitude of the coefficient suggests that the policy-induced education increase in regions with lower education before CSLs (e.g. Fujian, Jiangxi and Gansu) would be 1-2 years more than the regions like Beijing, Tianjin and Shanghai. Also note that the 
results suggest those provinces with more severe education deprivation before the 9-year CSLs increase more in education after the implement of the laws, which is meaningful to compress the regional inequality in China.

[Table 1 about here]

\subsection{Robustness and Tests}

\section{Consistent Results allowing region-specific linear time trends}

The estimation shares the similar concern as other DID estimation: time trends across the different regions may drive the estimation, whereas the different trends may be caused by other factors like economic growth and demand of schooling. This issue is also relevant to Stephens and Yang (2014) because they found the results become insignificant and wrong-signed when including region-specific linear trends. To shed light on this, I further control for province-specific birth cohort linear trends in column 3 of Table 1 . The estimates show that the impact of CSLs is robust to including these, suggesting that the other birth cohort linear trends across different regions should not be the first order factors influencing these.

\section{Consistent Results allowing non-linearity in prior education level}

Considering that the relationship between education deprivation prior to CSLs and the impact of CSLs may be non-linear, I further add the interaction between CSLs-Eligibility and square of demeaned proportion of those with fewer than 9 years education prior to CSLs into the regression in column 4 . The results find both the two interactions are significant and the F-test rejects the null hypothesis that both coefficients on the interactions equal to zero. The next sections show that the conclusions in this paper are consistent when using the square term as an additional instrument.

\section{Consistent Results by gender and by hype of hukou}

I divide the sample by gender and by hype of hukou -urban and rural to examine the heterogeneous impact of CSLs on education. Table A3 reports the results. Consisetent with the 
policy implementation, the results show that the impact of CSLs is larger for women and for rural hukou. Note that the F-tests across all columns are large enough except for the urban hukou sample, thus in the second stage results, I show the results by gender but not by type of hukou.

[Table A3 about here]

\section{Test 1: Other Confounding Factors or Other Policies?}

Using the impacts of CSLs as instruments requires the CSLs only influence the later health outcomes through education rather than other pathways. But it is true that the regions with lower education prior to CSLs are more likely to be those with weaker economies. Comparison between before- and after- CSLs in these regions may simply capture the time difference and may be correlated with other factors like economy development since the weaker economies have larger potential to grow faster. Although the results are robust when adding provincial specific linear trends, it is still a concern that the social norms or the development may not follow the linear trends in the provinces. Furthermore, it is also true that China implemented a series of policies in the 1980s and thus it is possible that the timing of CSLs and the interaction may pick up the variations of other policies. Considering the little chance to list all contemporaneous policies in different regions during that period and test their correlation with timing and enforcement of the CSLs. I directly test to what extent that CSLs may increase the years of education. The rationale is as follows. Different from the other laws in other countries, one important feature of the CSLs in China is the 9-year compulsory schooling for all the provinces. Ideally speaking, if the education increase identified in Table 1 and Figure 1 is due to the CSLs rather than other factors like economic development, local opinions towards to education or other policies, CSLs should increase the education up to and only up to nine-year schooling. By contrast, there is no evidence that other policies or confounding factors will shift the years of schooling only to 9 years.

Therefore, I construct a set of indicators for different years of education and conduct a series 
of regressions to test this. For example, for the indicator for any education, it equals to one if the individual received any formal education, and estimate equation (1) using this indicator as new dependent variable. Figure 3 reports the estimation for these different indicators. The intervals show the impact from $10^{\text {th }}$ percentile to $90^{\text {th }}$ percentile of the education prior to CSLs in the region. The grey and dashed line presents the threshold of CSLs. The coefficients keep positive and significant as long as the years of schooling not reaching the threshold - nine. Once the years of schooling exceeded nine, the impact of the policy diminished dramatically both for the main effects and the heterogeneous effects across regions. These findings suggest that the education improvement identified in Table 1 should originate from the CSLs rather than other unobserved factors like social norms or economy development.

[Figure 3 about here]

\section{Test 2: “Regression to the Mean" and Nutrition Status?}

I also provide some further suggestive evidence on "Exclusive Criteria" (i.e. CSLs only influence the later health outcomes through education rather than other pathways) by conducting two sets of placebo tests. The first set aims to test whether the impact or associations in Table 1 are only "regression to the mean" and test whether the potential instrumental variables just reflect the province-specific time trends. First, I restrict the sample to those cohorts earlier than the first affected cohort (i.e. the cohorts 2-15 years earlier than the first affected cohort). And then I suppose the implement year of CSLs to 5 years before, run the same regressions as equation (1) and report the estimates in the first two columns in Table 2. The insignificance and much smaller coefficients here (i.e. about one third compared to those in Table 1) provide no evidence that pre-trends or regressions to the mean matters much in this analysis.

[Table 2 about here]

The second set of placebo tests are conducted to test whether the impact of CSLs reflect the better nutrition of the individuals in the childhood or young adulthood. I use the individual height 
as an independent variable since height is proved to be a good measure for health and nutrition status of childhood and young adulthood and for economic development (Martorell and Habicht, 1986; Thomas and Strauss 1991; Deaton and Arora, 2009). If the impact of CSLs reflects the economic development or nutrition improvement, the effects should be captured in height. The estimates in the last two columns of Table 2 provide no evidence that CSLs are correlated with height. The estimates provide further evidence that CSLs improve education should only through the regulations and policies rather than nutrition improvement or economy development.

\section{Effects of Education on Health}

\subsection{Basic Empirical Results}

Before moving to the instrumental Two-Stage Least Squares (2SLS), I begin the analysis by first reporting the OLS estimates of the following equation:

$$
\text { (2) } \text { Health }_{i}=\theta_{0}+\theta_{1} E d u_{i}+\theta X_{i}+\delta_{s j t}+\epsilon_{i}
$$

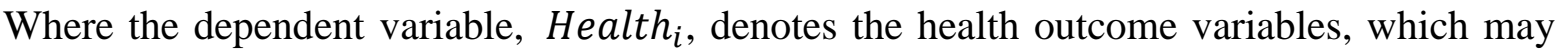
be self-reported health, underweight, smoking or cognition as described in Section 2.2, and all the other variables are the same with those in equation (1). Panel A of Table 3 reports the OLS estimates of $\theta_{1}$, showing that higher education is correlated with better health. All the results are significant except for the underweight. But note that the OLS results present the correlation rather than the causality. The sample size varies across columns because the information is not consistently collected in all the surveys. For example, the cognition tests (i.e. words recall and math calculation) are only collected by CFPS).

[Table 3 about here]

Panel B shows the reduced form results, whereas the education is replaced by the instrumental variables directly: 
(3) Health $_{i}=\lambda_{0}+\lambda_{1}$ Eligible $_{i j}+\lambda_{2}$ prop $_{j}^{\text {prior }<9} \times$ Eligible $_{i j}+\lambda X_{i}+\delta_{s j t}+\epsilon_{i}$

Since both of the instruments (i.e. Eligible $e_{i j}$ and $\operatorname{prop}_{j}^{\text {prior }<9} *$ Eligible $_{i j}$ ) predict higher education as Table 1 shows, it is expected that the sign on both variables (i.e. $\lambda_{1}$ and $\lambda_{2}$ ) in reduced form estimations should be correlated with better health outcomes. The estimates in Panel B provide consistent evidence for this: the sign of all the coefficients shows that increase in the two variables predicts better health outcomes.

I then use Two-Stage Least Squares (2SLS) to estimate the effects of education on health by using Eligible $_{i j}$ and the interaction prop $_{j}^{\text {prior }<9} \times$ Eligible $_{i j}$, as instruments:

$$
\text { (4) } \text { Health }_{i}=\beta_{0}+\beta_{1} \widehat{E d u_{i}}+\beta X_{i}+\delta_{s j t}+\epsilon_{i}
$$

where the $\widehat{E d u_{i}}$ is the predicted education value of equation (1) and all the other variables are the same with those in equation (1). Panel C presents the 2SLS estimates, which are of main interest in this analysis. Due to different samples, the F-tests in the first stage (i.e. Weak Instrumental Variable Tests) and Hansen tests (Over-Identification Tests) for the instruments are reported in the bottom of each column. ${ }^{15}$

Before moving to results for each outcome, it is meaningful to make a comparison between OLS results and 2SLS ones. As the results show, the 2SLS estimates are about three times larger in general. On one hand, it has been discussed in literature that the effects identified from 2SLS are local average treatment effects (LATE), implying the effects are for those compliers who are those affected by the CSLs (i.e. the ones increase education under CSLs and do not if without the laws). To shed light on this, I divide the whole sample by whether the individuals completing nine-year education and conduct OLS estimation for each group to investigate the associations of

\footnotetext{
15 The large F-statistics reject the hull hypothesis and provide evidence for significant first stage. This study did not report the detailed first stage for different outcomes but the results are available upon request. In general, the instruments also passed the over-identification tests, except for smoking.
} 
education with the health outcomes. The associations in the lower education group ( $<9$ years) tend to reflect the impact of education among the "complier" group since previous analysis shows the CSLs are effective only in the lower education group.

Table A4 presents the estimates, whereas Panel A shows the associations among the individuals with less than 9 years education and Panel B shows those for higher education group. Consistent with the hypothesis, the coefficients in Panel A are generally larger in magnitude than those in Panel B. The only exception is the results for smoking, and the reason could be due to income effects. In general, the results in Table A4 support the claim that the impact of education may be larger among compliers.

[Table A4 about here]

On the other hand, the OLS estimates may be biased to zero due to the classic measurement error in years of education because the values were reported by the respondents themselves and are used directly in this study. It is possible that these reported values may be wrong due to lack of awareness. ${ }^{16}$ if the measurement errors in education are classic, then it would be reasonable that the 2SLS estimates become larger.

The first column in Table 3 provides estimates for self-reported fair or poor health, indicating that an additional year increase in schooling decreases the probability of reporting fair or poor health by 2 percentage points, which is significant at 1 percent significance level. Considering the CHNS used four-point scale and the other two used five-point, I drop the CHNS sample and re-estimate the effects of schooling in column 2 of Table A5, which yield very consistent results. In the last colum, I further examined the effects of schooling on reporting excellent health and the 2SLS estimates show that an additional year of schooling increases the likelihood of reporting excellent health by about 1.2 percentage points.

\footnotetext{
16 There is no evidence whether individuals with higher education may be more likely to over- or under- report their own years of schooling.
} 
[Table A5 about here]

Column 2 of Panel B of Table 3 shows that an additional year of schooling leads to about 1.2 percentage points drop in underweight rate, suggesting an important role of education in improving nutrition status. However, the results are different from the findings: in the developed regions like the US and Europe, literature usually finds negative effect of education on BMI (Kemptner et al. 2010; Brunello et al. 2013). One probable reason is be that obesity is a more serious problem in the developed countries but not in developing countries like China. I also examine the effects of education on obesity in column 2 of Table A6, and no evidence is found for it. Consistently, estimates in the next three columns show that education in China increased BMI but the effects only exist in the sample with lower BMI. Therefore, these results suggest that education improve individual nutrition status in both developing countries like China and developed ones like US but the impact of education on BMI is different: schooling increases BMI in developing countries through decreasing underweight proportion but decreases BMI in developed countries via reducing the obesity rate.

[Table A6 about here]

Column 3 in Table 3 shows the effects of education on smoking. The 2SLS estimates suggest that an additional year in schooling reduces the likelihood of smoking by 1.5 percentage points, which are consistent with the findings of de Walque (2007) and Jensen and Lleras-Muney (2012). The last two columns examine cognition. This study provides first evidence for the causal effects of education on cognition among working age population, as the estimates in the last two columns of Table 3 suggest an additional year of schooling increases the cognition by 0.16 standard deviations for both words recalling and math calculation.

\subsection{Other Results and Robustness Checks}

\section{$\underline{\text { Results by Gender }}$}

With consideration that health and behaviors may be different in two sexes due to biological 
and cultural reasons and the impact of education may also differ, Figure $4 \mathrm{a}$ and $4 \mathrm{~b}$ shows the gender-specific 2SLS estimates. In Figure 4a, the effects of education on self-reported health and underweight are larger in magnitude among women but the difference between two sexes is insignificant due to large standard errors. However, the effects on smoking are much larger among men, and the possible explanation is the high smoking rate of them. Figure $4 \mathrm{~b}$ shows the effects on cognition. It can be found that the effects are similar between the two sexes for both outcomes.

[Figure $4 \mathrm{a}$ and $4 \mathrm{~b}$ about here]

\section{$\underline{\text { Results Using Different Weights and Independent Variable }}$}

Considering the CHNS are from nine provinces and combined the three samples together might put disproportionate weights on these provinces. I find the population within each province and weight the regressions by the population of the province divided by the number of observations, which yields very consistent estimates reported in Panel A of Table A7. In Panel B, I use whether the individuals complete junior high school as the key independent variable and conduct the 2SLS, which also yields consistent results in Table 3; the coefficients here are about ten times larger because those who complete junior high school have about 10 years more schoolings on average.

[Table A7 about here]

\section{$\underline{\text { Results Using Different Instruments }}$}

As mentioned above, I also use the square of proportion of people with lower than 9 years education interacting with the CSLs-eligibility as another instrument to check the robustness of the results. Figure 5a and 5b show the consistent, where the "IV1" denotes the instruments used above and "IV2" for the estimates with the additional instrument. Panel A of Figure 5a first show the 2SLS point estimate and $90 \%$ confidence intervals when just using CSL-eligibility as an instrument, which yields estimates with larger magnitude but also with the wider confidence 
interval making the difference statistically insignificant. All the estimates in Figure 5a and Figure $5 \mathrm{~b}$ show consistent estimates when adding the new variable as additional instrument, indicating that taking into account of the non-linear relationship between prior education level and education increase afterwards does not influence the results and conclusions in this paper.

[Figure 5a and $5 \mathrm{~b}$ about here]

\section{$\underline{\text { Results Adding Provincial-Specific Time Linear Trends }}$}

Although Table 1 shows the first stage is consistent and robust if adding provincial-specific linear trends in year of birth, it is unclear ex ante whether the second stage results may be influenced. Stephens and Yang (2014) also concluded that regional specific time trends can knock out many of the significant results in previous literature. Figures $6 \mathrm{a}$ and $6 \mathrm{~b}$ present the original estimates and the ones including provincial specific linear trends, which shows that adding trends does not influence the estimates for the effects on self-reported health (Panel A of Figure 6a) and cognition (Figure 6b). But doing so changes the estimates in magnitude for underweight and smoking, as the effect on underweight diminish but that on smoking are strengthened. However, the estimates do not provide evidence for significant differences between the coefficients under the two setting for both outcomes given the wide confidential intervals.

[Figure $6 \mathrm{a}$ and $6 \mathrm{~b}$ about here]

\section{Results Using A Trimmed Sample with Shorter Birth Cohort Span}

Another concern about the above analysis is that the sample covers a large span of birth cohorts (i.e. 1955-1990). I test the robustness of the results by trimming the sample to those born between the birth cohorts 15 years earlier or later than the CSL-eligible birth cohort. The estimates are reported in Figure $7 \mathrm{a}$ and $7 \mathrm{~b}$, showing a fairly consistent pattern in the trimmed sample.

[Figure 7a and Figure $7 \mathrm{~b}$ about here] 


\section{Understanding the Effects of Education on Health}

\subsection{Econometric Framework}

Due to data limitation and lack of exogenous variation, most of previous literature mainly focused on whether education has causal effects on health rather than how and why. And the mixed findings call for studies to understand the mechanisms through which education may have impact on health. To shed light on this, this section aims to investigate some potential pathways and quantitatively estimate how much proportion of the effects can be explained by these mechanisms.

There are many possible mechanisms from education to health. One pathway may be nutrition status. Conditional on other factors, individuals with higher education are more likely to know what is the healthy way to keep fit, which may be reflected on how they feed themselves in a scientific way. Another is health behavior. Many papers argue that the people with higher education are less likely to have bad health behaviors like smoking and drinking heavily and thus they are in better health status. Income is also an important factor since higher education predicts higher income and this allows the people to live in a life with higher quality like living in a house in a safer region and with better environment or having less financial pressure etc. In addition, cognition is also a potential channel because better cognition help individuals to make wiser and rational choices like choosing proper food and taking drugs in a right way if necessary, evaluate the potential risks in life and avoid the potential danger etc. Finally, since the behaviors of peers may have influence on your own, including life style and other unobservable factors that may influence health status like patience, depression etc., higher education may help to have better peers and thus the peer effects may be also an important pathway. Due to data availability, this study mainly focuses on the five mechanisms above: nutrition (measured by BMI), health behaviors measured by smoking, income, cognition measured by words recall and math 
calculation, and peer effects. ${ }^{17}$ However, it should be noted that the possible pathways are far more than these and that these pathways may not be independent from each other. For example, the nutrition status and cognition may have some overlap: those with higher cognition may have more nutrition knowledge and be more likely to purchase the food of high quality.

This section uses the reduced form framework since the key variables of education are more exogenous and follows the econometric framework in Cutler and Lleras-Muney (2010) to estimate the following equations:

(5) Health $_{i}=\gamma_{0}+\gamma_{1}$ Eligible $_{i j}+\gamma_{2}$ prop $_{j}^{\text {prior }<9} \times$ Eligible $_{i j}+\gamma X_{i}+\delta_{s j t}+\epsilon_{i}$ and

(5') Health $_{i}=\gamma_{0}^{\prime}+\gamma_{1}^{\prime}$ Eligible $_{i j}+\gamma_{2}^{\prime}{ }_{2}$ prop $_{j}^{\text {prior }}{ }^{\prime 29} \times$ Eligible $_{i j}+\gamma^{\prime} X_{i}+Z_{i}+\delta_{s j t}+\epsilon_{i}$

which $Z_{i}$ denotes the potential intermediate variables (i.e. BMI, smoking, income or cognition). Although the coefficients on Eligible $_{i j}$ and $\operatorname{prop}_{j}^{\text {prior }<9} \times$ Eligible $_{i j}$ reflect the impact of education, I mainly focus on the change of the coefficients prop $_{j}^{\text {prior }<9} \times$ Eligible $_{i j}, \gamma_{2}$, because the magnitude of $\gamma_{1}$ depends on how $\operatorname{prop}_{j}^{\text {prior }<9}$ is constructed (i.e. demeaned or minus a constant etc.) and thus it would be arbitrary if using the change of this coefficient to interpret the mechanisms. Specifically, we calculate the percentage reduction in magnitude from $\gamma_{2}$ to $\gamma_{2}^{\prime}$ and interpret it as the proportion of impact of education that could be explained by pathway $Z_{i}$.

But the above framework does not allow the analysis for peer effects since there is no specific variable to measure the peer effects in health. To shed some light on this, I calculate the health difference for two genders between those having completed junior high school and those having not among the birth cohorts that are ineligible for the CSLs, in the local provinces, denoted by $D_{g j}$, where the subscript $g$ stands for gender and $j$ for hukou province. ${ }^{18}$ Then

\footnotetext{
17 The income measure consistently measured in the three datasets is household income.

18 In practice, I run a regression for each province-gender group and estimate the
} 
estimate:

$$
\begin{aligned}
\left(5^{\prime \prime}\right) \text { Health }_{i} & =\gamma^{\prime \prime}{ }_{0}+\gamma^{\prime \prime}{ }_{1} \text { Eligible }_{i j}+\gamma^{\prime \prime}{ }_{2} \text { prop }_{j}^{\text {prior }<9} \times \text { Eligible }_{i j}+D_{g j}+D_{g j} \times \text { Eligible }_{i j}+D_{g j} \\
& \times \text { prop }_{j}^{\text {prior }<9} \times \text { Eligible }_{i j}+\gamma^{\prime \prime} X_{i}+Z_{i}+\delta_{s j t}+\epsilon_{i}
\end{aligned}
$$

the coefficients, $\gamma^{\prime \prime}{ }_{1}$ and $\gamma^{\prime \prime}{ }_{2}$, can be interpret as the impact of education when $D_{g j}$ equals to zero, and then I make a comparison between $\gamma^{\prime \prime}{ }_{2}$ and $\gamma_{2}$. The rationale is: if the impact of education is totally driven by peer effects, then the health outcome difference by education should be fully determined by the prior difference, which means that the peer effects should be absorbed by the interactions of Eligible $_{i j}$ and $\operatorname{prop}_{j}^{\text {prior }<9} \times$ Eligible $_{i j}$ with $D_{g j}$. Therefore, the difference between $\gamma^{\prime \prime}{ }_{2}$ and $\gamma_{2}$ shows the how much impact of education can be explained by peer effects. But it should be noted that this interaction might not only capture the peer effects but other factors like local specific education quality, culture etc. Thus the estimation may overestimate the part that could be explained by peer effects.

\subsection{Empirical Results on Mechanisms}

The basic results are reported in Table 4. I keep the sample with all the variables consistently available, which left about 35 thousand observations. The first column reports the benchmark results with only basic controls. The second column only adds the BMI categorical indicators (i.e. below $18.5,18.5$ to 22,22 to 25,25 to 30 and over 30 ), which makes the magnitude of the coefficient on the interaction prop $_{j}^{\text {prior }<9} \times$ Eligible $_{i j}$ decline from 0.0908 to 0.0803 , which means that the proportion that can be explained by BMI is $11.5 \%$ (i.e. $(0.0908-0.0803) / 0.0908=$ 11.5\%). Similarly, the columns from 3 to 5 separately add smoking, logarithm of household income, and cognition (i.e words recall and math calculation), which yields the magnitude of the interaction declining by $-0.2 \%, 15.3 \%$, and $12.6 \%$, respectively. The findings suggest that the smoking does not explain the impact of education on self-reported health, but both income and cognition could explain a significant proportion. Column 6 estimates the equation $\left(3^{\prime \prime \prime}\right)$ and the 
coefficient on the interaction changes from -0.0908 to -0.0740 , declining by $18.5 \%$. This finding suggests that peer effects are probably one important pathway from education to health. Column 7 reports the results when controlling for all these possible intermediate variables, which implies that all these factors mentioned above could explain up to $45 \%$ of the effects of education.

[Table 4 about here]

Since the above analysis based on a selective sample (about $30 \%$ of the original sample), it is a question whether the conclusions are robust or valid in the whole sample. Table A8 provides the results of the analysis based on the whole sample for specific outcomes. For each potential outcome, there are two columns separately reporting the basic results and the ones controlling for the potential channel. The results are generally consistent with what is reported in Table 4 . The nutrition status, smoking income cognition and peer effects can explain the effects of education by $12.6 \%, 0.3 \%, 22.1 \%, 12.6 \%$ and $9.9 \%$, respectively.

\section{[Table A8 about here]}

It should be noted that the above analysis provides novel but only suggestive evidence on the potential pathways from education to health, which is still far from satisfaction and conclusiveness. These findings suggest that there is no "thumb" pathway in the nexus between education and health as there is no variable explaining a really remarkable part of the effect. It is possible that the mixed findings in the previous literature may be due to the different effectiveness of the potential pathways and channels, and that it is not a simple question whether and why education affects health since the pathways may overlap with each other and endogenous to the outcomes. Research in the future may shed light on these questions.

\section{Conclusions and Discussion}

It is important to know whether and why education has causal impact on health. However, the controversial discussion in the literatures do not come to a consensus that education improves 
individual health but reveals the heterogeneity of education gradients in health across different countries. Theoretically, the causal effects of education are important key parameters in many economic models (Heckman 2007; Heckman 2010; Conti, Heckman, and Urzua 2010) and are helpful to understand the effectiveness and significance of the implications from them. Empirically, the different findings across different countries call for new findings in other countries, among different-aged population as well as evidence on the mechanisms to reconcile the heterogeneity and inconsistency. In practice, it is also important for the policy makers to understand the impact of the education policy on national health, especially in magnitude and effectiveness, given the large amount of fund devoted in healthcare and health insurance (Lei and Lin, 2009; Weinstein and Skinner 2010; Chen and Jin, 2012) and large population of older people and fast aging pace (Smith et al. 2014; Zhao et al. 2014).

This paper uses the exogenous temporal and geographical variation in Compulsory Schooling Laws establishment in China around 1986 to identify the effects of schooling on self-reported health, smoking, BMI and cognitive abilities and to unravel the potential mechanisms. The China's CSLs in 1986 is the first and formal laws in the largest developing country on the compulsory education, which persistently affects millions of individuals and households remarkably.

Above all, this paper hypothesize and provides sound evidence that the CSLs increased the education of the regions with prior lower education more rapidly when the laws became effective because of the "nine-year" compulsory schooling laws. The results imply that CSLs not only effectively increased the education level but also compressed the regional inequality across the nation by increasing the education in poorer areas in a larger magnitude.

This paper then provides sound evidence for the causal effects of education on health outcomes among working-age group in the largest developing country. Specifically, the results show that an additional year of schooling decreases 2-percentage points in reporting fair or poor health, 1-percentage points for underweight and 1.5-percentiage points for smoking. It is 
noteworthy that the effects identified are large in magnitude: further calculations based on the estimations indicate that education helps to explain over 20 percent of the health improvement from the 1950s birth cohorts to the1980s ones. ${ }^{19}$ The findings suggest education policies would be powerful tools for improving health. Thus these results build up the current growing literature investigating the causal effects of education on health. The results in this paper are consistent with Lleras-Muney (2005), van Kippersluis et al. (2011) and Kemptner et al. (2011) by providing evidence for the causal effects from the national representative sample in a developing country.

Finally, this study further examines the potential pathways and mechanisms why and how education influence health. The empirical results show that nutrition (measured by BMI), income, and cognition explain the impact of education on self-reported health by $11-13 \%, 15-22 \%$ and $13 \%$, separately. Suggestive evidence is provided that peer effects can also explain 10-18\% percent of the impact. These factors together can explain up to $45 \%$ of the effects of education. These novel results suggest the mixed findings in the previous literature may be due to the different effectiveness of the potential pathways and channels. The findings also call for research in the future to further shed light on other mechanisms.

However, there are also a couple of pitfalls that this paper suffers. Although the CSLs are used widely in the literature to estimate the causal impact of education, this methodology is not perfect due to potential endogenous policies decisions in timing and intensity. Since this paper uses the interaction between geographical intensity measure and CSLs eligibility, which does not solely rely on the timing or the intensity, it is still questionable for the instruments' exclusive criteria: in a country with fast developing pace and intense reform like China, it is really difficult to claim that there are no other unobservable policies that correlated with the instruments used in this paper. Although the robustness checks and placebo tests suggest the validity of the instrument, I still cannot rule out all the possibilities that may be correlated with the education increase and health outcomes at the same time.

\footnotetext{
19 The details about the calculation are available upon request.
} 
In addition, this paper also does not take into account of the spillover effects or externalities of education. Since these externalities are probably positive (Acemoglu and Angrist 2000) - those who still receive no formal schooling may also improve their health outcomes due to health of others being better, the estimates in this paper would underestimate the effect as a result.

Finally, though this study provides some suggestive evidence on a couple of mechanisms, it is far from satisfaction. For one thing, it is still a question how much other potential mechanisms may explain the causal effects of education. For the other, it is also possible that the heterogeneity in mechanisms also exist in different countries and in different periods. Due to data limitation, I leave these questions to studies in the future for us to better understand the effects of education on health. 


\section{References}

Acemoglu, Daron, and Joshua Angrist. "How large are human-capital externalities? evidence from compulsory-schooling laws." NBER Macroeconomics Annual 2000, Volume 15. MIT PRess, 2001. 9-74.

Acemoglu, Daron, and Simon Johnson. "Disease and Development: The Effect of Life Expectancy on Economic Growth." Journal of Political Economy 115.6 (2007): 925-985.

Adler, Nancy E., et al. "Socioeconomic status and health: the challenge of the gradient." American psychologist 49.1 (1994): 15.

Albouy, Valerie, and Laurent Lequien. "Does compulsory education lower mortality?." Journal of health economics 28.1 (2009): 155-168.

Banks, James, and Fabrizio Mazzonna. "The effect of education on old age cognitive abilities: evidence from a regression discontinuity design*." The Economic Journal 122.560 (2012): 418-448.

Benyamini, Yael, and Ellen L. Idler. "Community studies reporting association between self-rated health and mortality additional studies, 1995 to 1998."Research on Aging 21.3 (1999): $392-401$.

Berger, Mark C., and J. Paul Leigh. "The effect of alcohol use on wages."Applied Economics 20.10 (1988): 1343-1351.

Brunello, Giorgio, Daniele Fabbri, and Margherita Fort. "The causal effect of education on body mass: Evidence from Europe." Journal of Labor Economics31.1 (2013): 195-223.

Case, Anne, Angela Fertig, and Christina Paxson. "The lasting impact of childhood health and circumstance." Journal of health economics 24.2 (2005): 365-389.

Case, Anne, and Christina Paxson. "The Long Reach of Childhood Health and Circumstance: Evidence from the Whitehall II Study*." The Economic Journal121.554 (2011): F183-F204. 
Cervellati, Matteo, and Uwe Sunde. "Human capital formation, life expectancy, and the process of development." American Economic Review (2005): 1653-1672.

Christenson, Bruce A., and Nan E. Johnson. "Educational inequality in adult mortality: an assessment with death certificate data from Michigan."Demography 32.2 (1995): 215-229.

Clark, Damon, and Heather Roayer. "The effect of education on adult mortality and health: Evidence from Britain." The American Economic Review 103.6 (2013): 2087-2120.

Conti, Gabriella, James Heckman, and Sergio Urzua. "The education-health gradient." The American economic review 100.2 (2010): 234.

Cutler, David M., Edward L. Glaeser, and Jesse M. Shapiro. "Why Have Americans Become More Obese?." The Journal of Economic Perspectives 17.3 (2003): 93-118.

Cutler, David M., and Adriana Lleras-Muney. Education and health: evaluating theories and evidence. No. w12352. National Bureau of Economic Research, 2006.

Cutler, David M., and Adriana Lleras-Muney. "Understanding differences in health behaviors by education." Journal of health economics 29.1 (2010): 1-28.

Cutler, David M., and Adriana Lleras-Muney. Education and health: insights from international comparisons. No. w17738. National Bureau of Economic Research, 2012.

Cutler, David, Wei Huang, and Adriana Lleras-Muney. "When Does Education Matter? The Protective Effect of Education for Cohorts Graduating in Bad Times." Social Science \& Medicine (2014)

Deaton, Angus S., and Christina Paxson. "Mortality, education, income, and inequality among American cohorts." Themes in the Economics of Aging. University of Chicago Press, 2001. 129-170.

Deaton, Angus. "Health, income and inequality." National Bureau of Economic Research Reporter: Research Summary. Retrieved August 15 (2003): 2009. 
Deaton, Angus, and Raksha Arora. "Life at the top: the benefits of height." Economics \& Human Biology 7.2 (2009): 133-136.

De Walque, Damien. "Does education affect smoking behaviors?: Evidence using the Vietnam draft as an instrument for college education." Journal of health economics 26.5 (2007): 877-895.

Elo, Irma T., and Samuel H. Preston. "Educational differentials in mortality: United States, 1979-1985." Social science \& medicine 42.1 (1996): 47-57.

Filmer, Deon, and Lant Pritchett. "The impact of public spending on health: does money matter?." Social science \& medicine 49.10 (1999): 1309-1323.

Finkelstein, Eric A., Christopher J. Ruhm, and Katherine M. Kosa. "Economic causes and consequences of obesity." Annu. Rev. Public Health 26 (2005): 239-257.

Fletcher, Jason. "New evidence of the effects of education on health in the US: Compulsory schooling laws Revisited." Social Science \& Medicine (2014).

Fogel, Robert W. "Economic Growth, Population Theory, and Physiology: The Bearing of Long-Term Processes on the Making of Economic Policy." American Economic Review 84.3 (1994): 369-95.

Galor, Oded, and David N. Weil. "Population, technology, and growth: From Malthusian stagnation to the demographic transition and beyond." American economic review (2000): 806-828.

Gathmann, Christina, Hendrik Jürges, and Steffen Reinhold. "Compulsory schooling reforms, education and mortality in twentieth century Europe." Social Science \& Medicine (2014).

Gilman, Stephen E., et al. "Educational attainment and cigarette smoking: a causal association?." International Journal of Epidemiology 37.3 (2008): 615-624.

Grossman, Michael. "The demand for health: a theoretical and empirical investigation." NBER 


\section{Books (1972).}

Grossman, Michael. "Education and nonmarket outcomes." Handbook of the Economics of Education 1 (2006): 577-633.

Hanushek, Eric A. "Economic growth in developing countries: The role of human capital." Economics of Education Review 37 (2013): 204-212.

Hanushek, Eric A., and Ludger Woessmann. "The role of cognitive skills in economic development." Journal of economic literature (2008): 607-668.

Heckman, James J. "The economics, technology, and neuroscience of human capability formation." Proceedings of the national Academy of Sciences 104.33 (2007): 13250-13255.

Heckman, James J. "Building Bridges between Structural and Program Evaluation Approaches to Evaluating Policy." Journal of Economic Literature48.2 (2010): 356-98.

Huang, Wei, et al. "Health, height, height shrinkage, and SES at older ages: evidence from China." American Economic Journal: Applied Economics 5.2 (2013): 86-121.

Huang, Wei, and Yi Zhou. "Effects of education on cognition at older ages: Evidence from China's Great Famine." Social Science \& Medicine 98 (2013): 54-62.

Idler, Ellen L., and Yael Benyamini. "Self-rated health and mortality: a review of twenty-seven community studies." Journal of health and social behavior (1997): 21-37.

Jayachandran, Seema, and Adriana Lleras-Muney. "Life Expectancy and Human Capital Investments: Evidence from Maternal Mortality Declines." The Quarterly Journal of Economics 124.1 (2009): 349-397.

Jensen, Robert, and Adriana Lleras-Muney. "Does staying in school (and not working) prevent teen smoking and drinking?." Journal of health economics31.4 (2012): 644-657.

Jürges, Hendrik, Steffen Reinhold, and Martin Salm. "Does schooling affect health behavior? Evidence from the educational expansion in Western Germany." Economics of Education 
Review 30.5 (2011): 862-872.

Kawada, Tomoyuki. "Question Context, Ethnic Difference, and Self-Rated Health." American journal of public health 104.1 (2014): e3-e3.

Kemptner, Daniel, Hendrik Jürges, and Steffen Reinhold. "Changes in compulsory schooling and the causal effect of education on health: Evidence from Germany." Journal of Health Economics 30.2 (2011): 340-354.

Kenkel, Donald S. "Health behavior, health knowledge, and schooling." Journal of Political Economy (1991): 287-305.

Kitagawa, Evelyn M., and Philip M. Hauser. Differential mortality in the United States: A study in socioeconomic epidemiology. Vol. 35. Cambridge, MA: Harvard University Press, 1973.

Lager, Anton Carl Jonas, and Jenny Torssander. "Causal effect of education on mortality in a quasi-experiment on 1.2 million Swedes." Proceedings of the National Academy of Sciences 109.22 (2012): 8461-8466.

Lei, Xiaoyan, et al. "Gender differences in cognition among older adults in China." Journal of Human Resources 47.4 (2012): 951-971.

Leigh, J. Paul, and Rachna Dhir. "Schooling and frailty among seniors."Economics of Education Review 16.1 (1997): 45-57.

Lleras-Muney, Adriana. "The relationship between education and adult mortality in the United States." The Review of Economic Studies 72.1 (2005): 189-221.

Martorell, Reynaldo, and Jean-Pierre Habicht. "Growth in early childhood in developing countries." (1986): 241-62.

McArdle, John J., et al. "Comparative longitudinal structural analyses of the growth and decline of multiple intellectual abilities over the life span." Developmental psychology 38.1 (2002): 115. 
Meara, Ellen. Why is health related to socioeconomic status?. No. w8231. National Bureau of Economic Research, 2001.

Naidu, A. N., and N. P. Rao. "Body mass index: a measure of the nutritional status in Indian populations." European journal of clinical nutrition 48 (1994): S131-40.

Newhouse, Joseph P., and Rand Corporation. Insurance Experiment Group, eds. Free for all?: lessons from the RAND health insurance experiment. Harvard University Press, 1993.

Naidu, A. N., and N. P. Rao. "Body mass index: a measure of the nutritional status in Indian populations." European journal of clinical nutrition 48 (1994): S131-40.

Oreopoulos, Philip, and Kjell G. Salvanes. "Priceless: The nonpecuniary benefits of schooling." The Journal of Economic Perspectives (2011): 159-184.

Park, Cheolsung, and Changhui Kang. "Does education induce healthy lifestyle?." Journal of Health Economics 27.6 (2008): 1516-1531.

Pincus, Theodore, Leigh F. Callahan, and Richard V. Burkhauser. "Most chronic diseases are reported more frequently by individuals with fewer than 12 years of formal education in the age 18-64 United States population." Journal of Chronic Diseases 40.9 (1987): 865-874.

Rolland-Cachera, Marie-Françoise, et al. "Body Mass Index variations: centiles from birth to 87 years." European journal of clinical nutrition 45.1 (1991): 13-21.

Sander, William. "Schooling and quitting smoking." The Review of Economics and Statistics (1995): 191-199.

Silles, Mary A. "The causal effect of education on health: Evidence from the United Kingdom." Economics of Education Review 28.1 (2009): 122-128.

Smith, James, John Strauss, Yaohui Zhao*, "Healthy Ageing in China," The Journal of the Economics of Ageing, forthcoming

Soares, Rodrigo R. "Mortality reductions, educational attainment, and fertility choice." American 
Economic Review (2005): 580-601.

Sobal, Jeffery, and Albert J. Stunkard. "Socioeconomic status and obesity: a review of the literature." Psychological bulletin 105.2 (1989): 260.

Strauss, John, and Duncan Thomas. "Health, nutrition, and economic development." Journal of economic literature (1998): 766-817.

Thomas, Duncan, John Strauss, and Maria-Helena Henriques. "How does mother's education affect child height?." Journal of human resources (1991): 183-211.

US Department of Health and Human Services. "The health consequences of smoking — 50 years of progress: A report of the surgeon general." Atlanta, GA: US Department of Health and Human Services, Centers for Disease Control and Prevention, National Center for Chronic Disease Prevention and Health Promotion, Office on Smoking and Health 17 (2014).

Van Kippersluis, Hans, Owen O’Donnell, and Eddy van Doorslaer. "Long-Run Returns to Education Does Schooling Lead to an Extended Old Age?." Journal of human resources 46.4 (2011): 695-721.

Weinstein, Milton C., and Jonathan A. Skinner. "Comparative effectiveness and health care spending_implications for reform." New England Journal of Medicine 362.5 (2010): 460-465.

Zhang, Junsen, et al. "Economic returns to schooling in urban China, 1988 to 2001." Journal of Comparative Economics 33.4 (2005): 730-752.

Zhao, Yaohui, James P. Smith, and John Strauss. "Can China age healthily?." The Lancet 384.9945 (2014): 723-724. 
Table 1. OLS Estimation for Impact of CSLs on Years of Schooling

\begin{tabular}{lcccc}
\hline \multirow{2}{*}{ Variables } & $(1)$ & $(2)$ & $(3)$ & $(4)$ \\
& \multicolumn{2}{c}{ Dependent variable is Years of Schooling } \\
\hline CSLs Eligibility & & & & \\
& $1.111^{* * *}$ & $1.131^{* * *}$ & $1.236^{* * *}$ & $1.008^{* * * *}$ \\
Pr(less than 9-year education) $*$ & $(0.379)$ & $(0.358)$ & $(0.380)$ & $(0.356)$ \\
Eligibility & & $4.058^{* * *}$ & $6.137 * * *$ & $3.397 * * *$ \\
Pr(less than 9-year education) & & $(0.641)$ & $(1.433)$ & $(0.609)$ \\
square * Eligibility & & & & $10.70 * * *$ \\
& & & & $(2.163)$ \\
Observations & 114,647 & 114,647 & 114,647 & 114,647 \\
R-squared & 0.249 & 0.251 & 0.255 & 0.251 \\
F-statistic for all the variables & 8.594 & 23.47 & 16.41 & 22.25 \\
P-value for the F-test & 0.003 & 0.000 & 0.000 & 0.000 \\
Provincial YoB Linear Trends & & & $\mathrm{X}$ & \\
\hline \hline
\end{tabular}

Notes: Data source is CFPS, CHIPs and CHNS. Robust standard errors in parentheses are clustered at province-year of birth level. Covariates include indicators of type of hukou (Urban/Rural), Year of birth, Age (three-year categories), Hukou Province, Survey year and all interactions of province, year and sample. The Pr(less than 9-year education) variables are demeaned value so that the coefficient on CSLs Eligibility should be interpreted as the impact at mean value.

*** $\mathrm{p}<0.01$, ** $\mathrm{p}<0.05, * \mathrm{p}<0.1$. 
Table 2. Impacts of Compulsory Schooling Laws Placebo tests

\begin{tabular}{|c|c|c|c|c|}
\hline \multirow{3}{*}{$\begin{array}{l}\text { Settings } \\
\text { VARIABLES }\end{array}$} & $(1)$ & $(2)$ & (3) & (4) \\
\hline & \multicolumn{2}{|c|}{$\begin{array}{l}\text { CSLs ineligible (2-15 years earlier) } \\
\text { and suppose CSLs } 5 \text { years before }\end{array}$} & \multicolumn{2}{|c|}{ Use Height as Dep. Var. } \\
\hline & \multicolumn{2}{|c|}{ Years of Schooling } & \multicolumn{2}{|c|}{ Height $(\mathrm{cm})$} \\
\hline CSLs Eligibility & $\begin{array}{c}0.266 \\
(0.622)\end{array}$ & $\begin{array}{c}0.257 \\
(0.617)\end{array}$ & $\begin{array}{c}0.466 \\
(0.447)\end{array}$ & $\begin{array}{c}0.463 \\
(0.448)\end{array}$ \\
\hline $\begin{array}{l}\text { Pr(less than 9-year education) } \\
* \text { Eligibility }\end{array}$ & & $\begin{array}{c}1.415 \\
(0.940)\end{array}$ & & $\begin{array}{l}-0.353 \\
(0.570)\end{array}$ \\
\hline Observations & 39,511 & 39,510 & 87,137 & 87,137 \\
\hline R-squared & 0.305 & 0.305 & 0.546 & 0.546 \\
\hline F-statistic for all the variables & 0.183 & 1.185 & 1.086 & 0.728 \\
\hline $\mathrm{P}$-value for the F-tests & 0.669 & 0.306 & 0.298 & 0.483 \\
\hline
\end{tabular}

Notes: Data source is CFPS, CHIPs and CHNS. Robust standard errors in parentheses are clustered at province-year of birth level. Covariates are the same as Table 1. Columns 1 and 2 use the CSLs ineligible sample (i.e. aged 17-30 when CSLs started in local province) and suppose CSLs happened 5 years before, conduct the same regression in Table 1 to check the pre-trends. Columns 3 and 4 use the current height in centimeter as dependent variable to check whether the education policy has any impact on the nutrition status of the childhood and young adulthood.

$* * * \mathrm{p}<0.01, * * \mathrm{p}<0.05, * \mathrm{p}<0.1$ 
Table 3. Impact of Education on Health

\begin{tabular}{|c|c|c|c|c|c|}
\hline VARIABLES & $\begin{array}{c}(1) \\
\text { Health Fair or } \\
\text { Poor (Yes = 1) }\end{array}$ & $\begin{array}{c}(2) \\
\text { Underweight } \\
(\text { Yes = 1) }\end{array}$ & $\begin{array}{c}(3) \\
\text { Smoker } \\
(\text { Yes = 1) }\end{array}$ & $\begin{array}{l}\text { (4) } \\
\text { Words recall Z- } \\
\text { score }\end{array}$ & $\begin{array}{c}\text { (5) } \\
\text { Math Ability Z- } \\
\text { Score }\end{array}$ \\
\hline Mean of Dependent Var. & 0.190 & 0.077 & 0.264 & 0.000 & 0.000 \\
\hline \multicolumn{6}{|l|}{ Panel A. OLS Estimation } \\
\hline Years of Schooling & $\begin{array}{c}-0.00728 * * * \\
(0.000451)\end{array}$ & $\begin{array}{l}-0.000192 \\
(0.000321)\end{array}$ & $\begin{array}{c}-0.00522 * * * \\
(0.000434)\end{array}$ & $\begin{array}{l}0.107 * * * \\
(0.00142)\end{array}$ & $\begin{array}{l}0.152 * * * \\
(0.00139)\end{array}$ \\
\hline Observations & 88,971 & 85,275 & 105,634 & 34,999 & 28,192 \\
\hline R-squared & 0.096 & 0.057 & 0.377 & 0.382 & 0.560 \\
\hline \multicolumn{6}{|l|}{ Panel B. Reduced Form Results } \\
\hline CSLs Eligibility & $\begin{array}{c}-0.0620 * * * \\
(0.0217)\end{array}$ & $\begin{array}{l}-0.00319 \\
(0.0174)\end{array}$ & $\begin{array}{c}-0.0760 * * * \\
(0.0205)\end{array}$ & $\begin{array}{c}0.317 * * * \\
(0.0815)\end{array}$ & $\begin{array}{c}0.287 * * * \\
(0.0973)\end{array}$ \\
\hline $\begin{array}{l}\text { Pr(less than 9-year education) * } \\
\text { Eligibility }\end{array}$ & $\begin{array}{c}-0.0761 * * \\
(0.0328)\end{array}$ & $\begin{array}{c}-0.0702 * * \\
(0.0308)\end{array}$ & $\begin{array}{l}-0.0145 \\
(0.0357)\end{array}$ & $\begin{array}{c}0.331 * * * \\
(0.111)\end{array}$ & $\begin{array}{c}0.102 \\
(0.141)\end{array}$ \\
\hline Observations & 88,971 & 85,275 & 105,634 & 34,999 & 28,192 \\
\hline R-squared & 0.092 & 0.057 & 0.375 & 0.188 & 0.189 \\
\hline \multicolumn{6}{|l|}{ Panel C. 2SLS Estimation } \\
\hline Years of Schooling & $\begin{array}{c}-0.0204 * * * \\
(0.00643)\end{array}$ & $\begin{array}{l}-0.0118^{*} \\
(0.00626)\end{array}$ & $\begin{array}{c}-0.0146 * * \\
(0.00716)\end{array}$ & $\begin{array}{l}0.157 * * * \\
(0.0266)\end{array}$ & $\begin{array}{c}0.158 * * * \\
(0.0334)\end{array}$ \\
\hline Observations & 88,971 & 85,275 & 105,634 & 34,999 & 28,192 \\
\hline \multicolumn{6}{|l|}{ First Stage F-tests } \\
\hline F-Statistics & 27.24 & 28.09 & 25.93 & 12.11 & 8.903 \\
\hline P-values for IV F-tests & 0.000 & 0.000 & 0.000 & 0.000 & 0.000 \\
\hline \multicolumn{6}{|l|}{ Over-identification tests } \\
\hline Hansen Statistics & 2.285 & 1.235 & 9.689 & 3.583 & 0.290 \\
\hline Hansen-P Values & 0.131 & 0.267 & 0.002 & 0.058 & 0.590 \\
\hline
\end{tabular}

Notes: Data source is CFPS, CHIPs and CHNS. Robust standard errors in parentheses are clustered at province-year of birth level. Covariates are the same as those in Table 1. Panel A provides the results of OLS estimation, Panel B shows the reduced-form results by replacing the years of schooling by the instruments, and Panel C shows the 2SLS estimation. Bottom of the table reports the First-Stage F-tests for first stage and over-identification tests. Different columns show the results for different dependent variables.

$* * * \mathrm{p}<0.01, * * \mathrm{p}<0.05, * \mathrm{p}<0.1$ 
Table 4. Channel Analysis

\begin{tabular}{|c|c|c|c|c|c|c|c|}
\hline \multirow{3}{*}{ VARIABLES } & (1) & (2) & (3) & $(4)$ & $(5)$ & (6) & (7) \\
\hline & \multicolumn{7}{|c|}{ Health Fair or Poor $($ Yes $=1)$} \\
\hline & Basic & $\begin{array}{c}\text { Basic + } \\
\text { BMI }\end{array}$ & $\begin{array}{c}\text { Basic + } \\
\text { Smoking }\end{array}$ & $\begin{array}{l}\text { Basic + } \\
\text { Income }\end{array}$ & $\begin{array}{c}\text { Basic + } \\
\text { Cognition }\end{array}$ & $\begin{array}{c}\text { Basic + Peer } \\
\text { Effects }\end{array}$ & $\begin{array}{c}\text { Basic + } \\
\text { All }\end{array}$ \\
\hline $\begin{array}{l}\text { Part of impact can be } \\
\text { explained }\end{array}$ & & $11.5 \%$ & $-0.2 \%$ & $15.3 \%$ & $12.6 \%$ & $18.5 \%$ & $45.1 \%$ \\
\hline CSLs Eligibility & $\begin{array}{l}-0.0584 * \\
(0.0323)\end{array}$ & $\begin{array}{l}-0.0608 * \\
(0.0325)\end{array}$ & $\begin{array}{l}-0.0590^{*} \\
(0.0322)\end{array}$ & $\begin{array}{l}-0.0559 * \\
(0.0319)\end{array}$ & $\begin{array}{l}-0.0464 \\
(0.0324)\end{array}$ & $\begin{array}{l}-0.0555^{*} \\
(0.0326)\end{array}$ & $\begin{array}{l}-0.0482 \\
(0.0324)\end{array}$ \\
\hline $\begin{array}{l}\text { Pr(less than 9-year } \\
\text { education) * Eligibility } \\
\text { Initial difference }\end{array}$ & $\begin{array}{l}-0.0908 * * \\
(0.0383)\end{array}$ & $\begin{array}{l}-0.0803 * * \\
(0.0386)\end{array}$ & $\begin{array}{l}-0.0910 * * \\
(0.0383)\end{array}$ & $\begin{array}{l}-0.0768 * * \\
(0.0383)\end{array}$ & $\begin{array}{l}-0.0794 * * \\
(0.0380)\end{array}$ & $\begin{array}{c}\mathbf{- 0 . 0 7 4 0 *} \\
(\mathbf{0 . 0 4 3 7 )} \\
0.0203 \\
(0.0615)\end{array}$ & $\begin{array}{r}\mathbf{- 0 . 0 4 9 9} \\
(\mathbf{0 . 0 4 4 0 )} \\
0.0110 \\
(0.0599)\end{array}$ \\
\hline $\begin{array}{l}\text { CSLs eligiblity } * \text { Initial } \\
\text { difference } \\
\text { Pr(less than 9-year } \\
\text { education) } * \text { Eligibility * }\end{array}$ & & & & & & $\begin{array}{c}0.0346 \\
(0.0694) \\
0.253 \\
(0.341)\end{array}$ & $\begin{array}{c}0.0308 \\
(0.0685) \\
0.171 \\
(0.339)\end{array}$ \\
\hline $\begin{array}{l}\text { Observations } \\
\text { R-squared } \\
\end{array}$ & $\begin{array}{c}35,049 \\
0.121 \\
\end{array}$ & $\begin{array}{c}35,049 \\
0.126 \\
\end{array}$ & $\begin{array}{c}35,049 \\
0.121 \\
\end{array}$ & $\begin{array}{c}35,049 \\
0.129 \\
\end{array}$ & $\begin{array}{c}35,049 \\
0.128 \\
\end{array}$ & $\begin{array}{c}35,049 \\
0.121 \\
\end{array}$ & $\begin{array}{c}35,049 \\
0.137 \\
\end{array}$ \\
\hline
\end{tabular}

Notes: Data source is CFPS, CHIPs and CHNS. Robust standard errors in parentheses are clustered at province-year of birth level. Only the observations with the consistent measures are kept. Covariates in the basic model are the same as those in Table 1.

$* * * \mathrm{p}<0.01, * * \mathrm{p}<0.05, * \mathrm{p}<0.1$. 


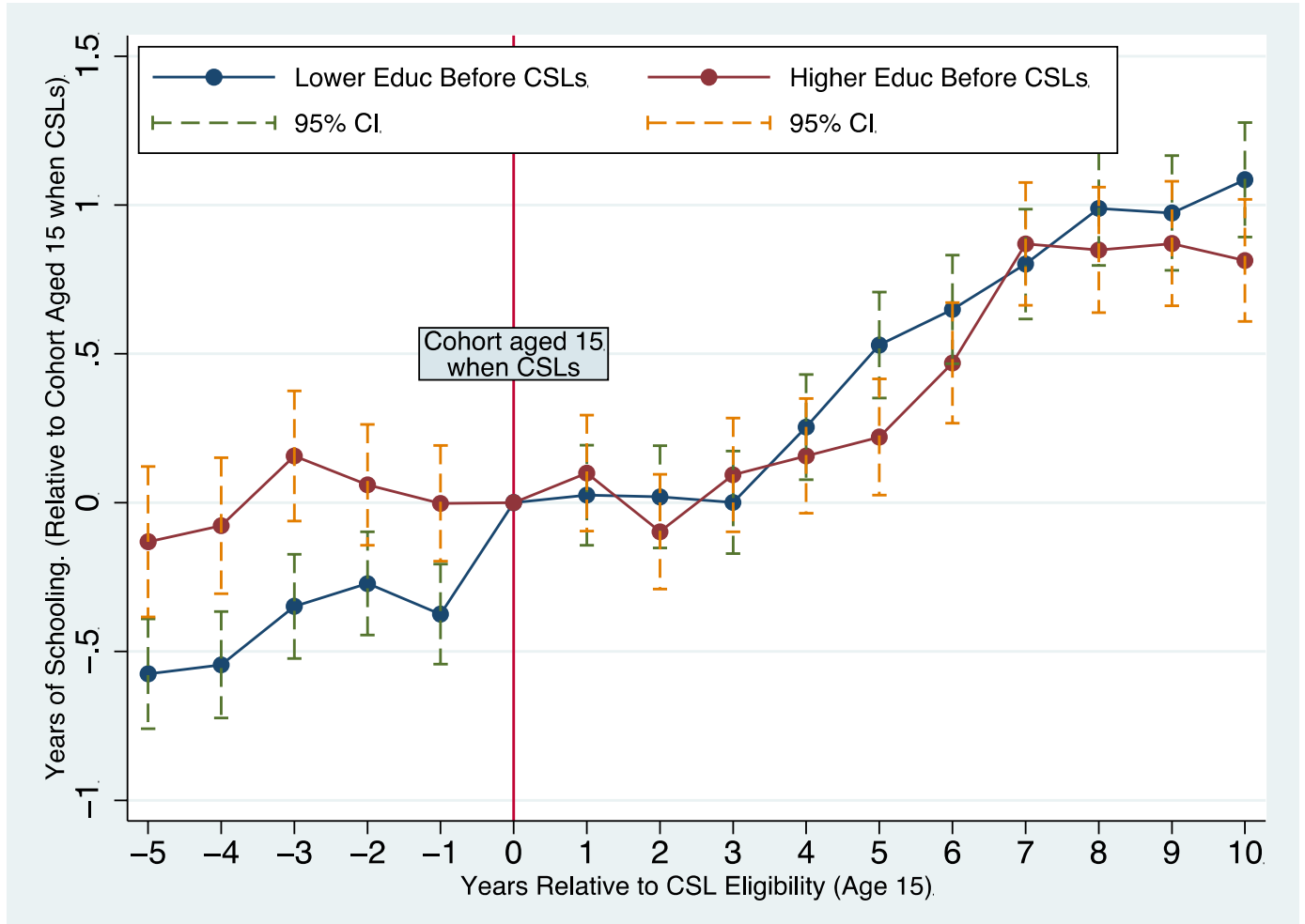

\section{Figure 1. Years of Schooling Increase over the Time Relative to CSLs, by Education Level Before the Laws}

Notes: Data source is CFPS, CHIPs and CHNS. The sample is divided by the median value of proportion of individuals with less than 9-year education prior to CSLs. For each subsample, regression is conducted to estimate how the years of schooling change over the time relative to the CSLs eligibility, with controlling for gender indicator and dummies for hukou province, survey year, sample (CHNS/CFPS/CHIPS) and all of their interactions. The reference group is the cohort just eligible for the CSLs (i.e. the birth cohorts aged 15 when CSLs started in the local province) for each subsample (i.e. both the point estimation and the confidential intervals are zero in the figure). Both point estimation and $95 \%$ confidential intervals are reported for the coefficients on the dummies of the relative years to the CSLs eligibility. 


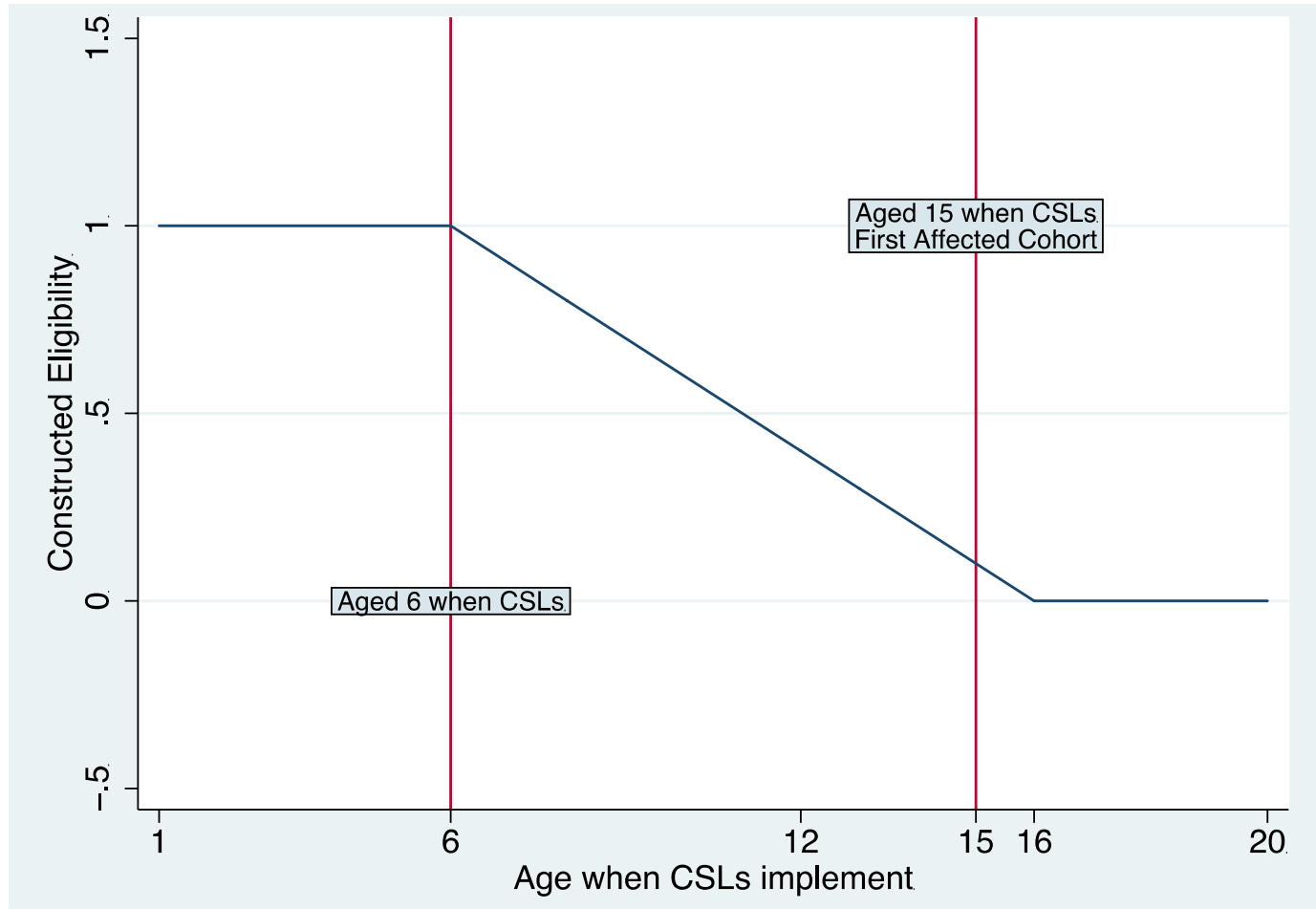

Figure 2. CSLs Eligibility Construction

Notes: The $\mathrm{X}$-axis is the individual age when CSLs were just effective in the local province and the $\mathrm{y}$-axis is the value for the eligibility, which equals to one if the individual is fully eligible to the CSLs (i.e. aged 6 or below) and equals to zero if the individual is ineligible (i.e. aged 16 or above). A linear function is assumed for the ages in between. 


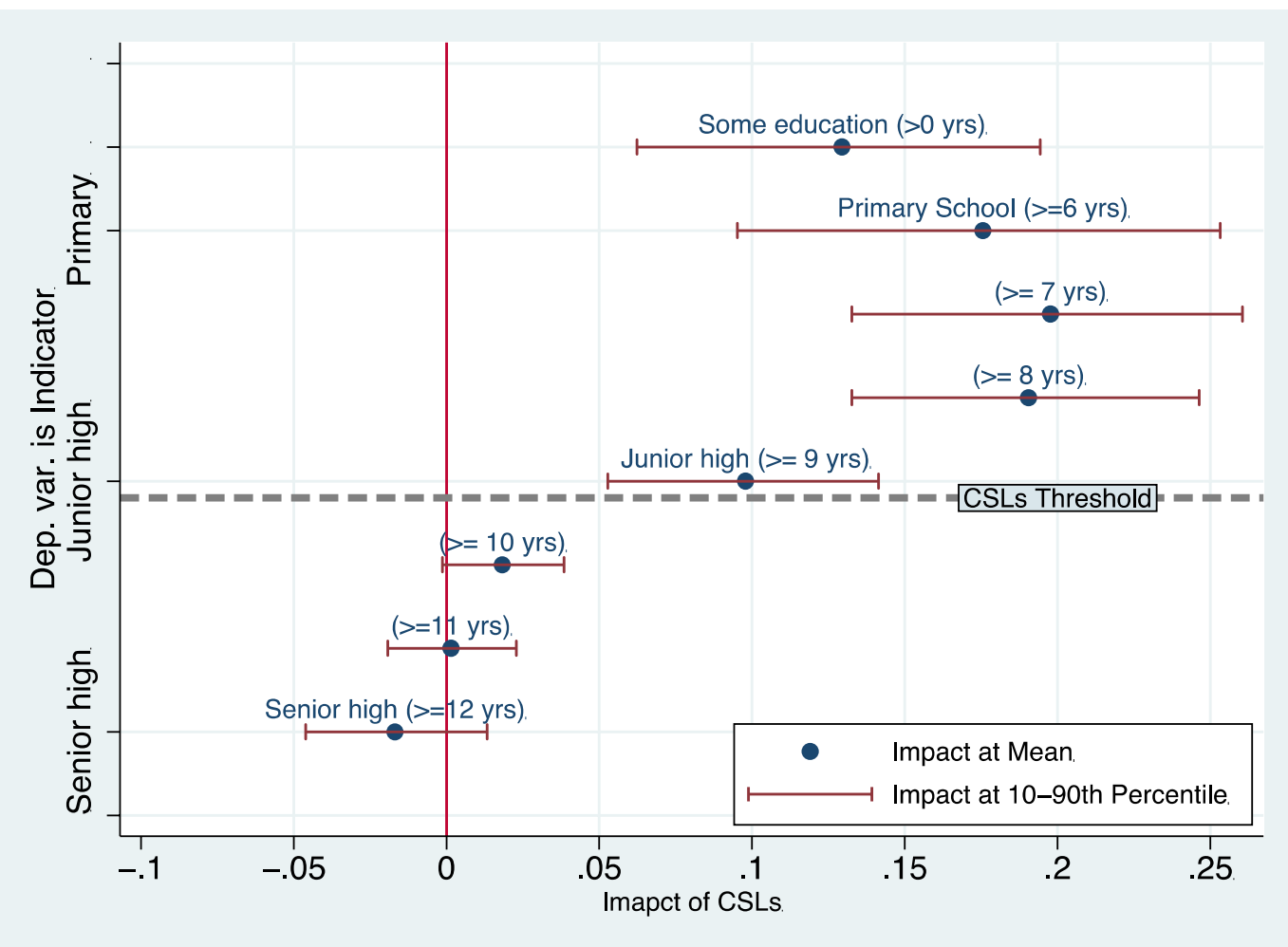

Figure 3. Impact of CSLs on Years of Schooling at Different Education Levels

Notes: Data source is CFPS, CHIPs and CHNS. Each row reports a specific the OLS estimation when the dependent variable is the indicator for completing the corresponding years of education (as marked). The independent variables are described in equation (1). The points in the figure report the coefficients on CSLs-eligibility and the intervals show the impact from $10^{\text {th }}$ percentile to $90^{\text {th }}$ percentile of the prior education level calculated from the OLS estimates. 


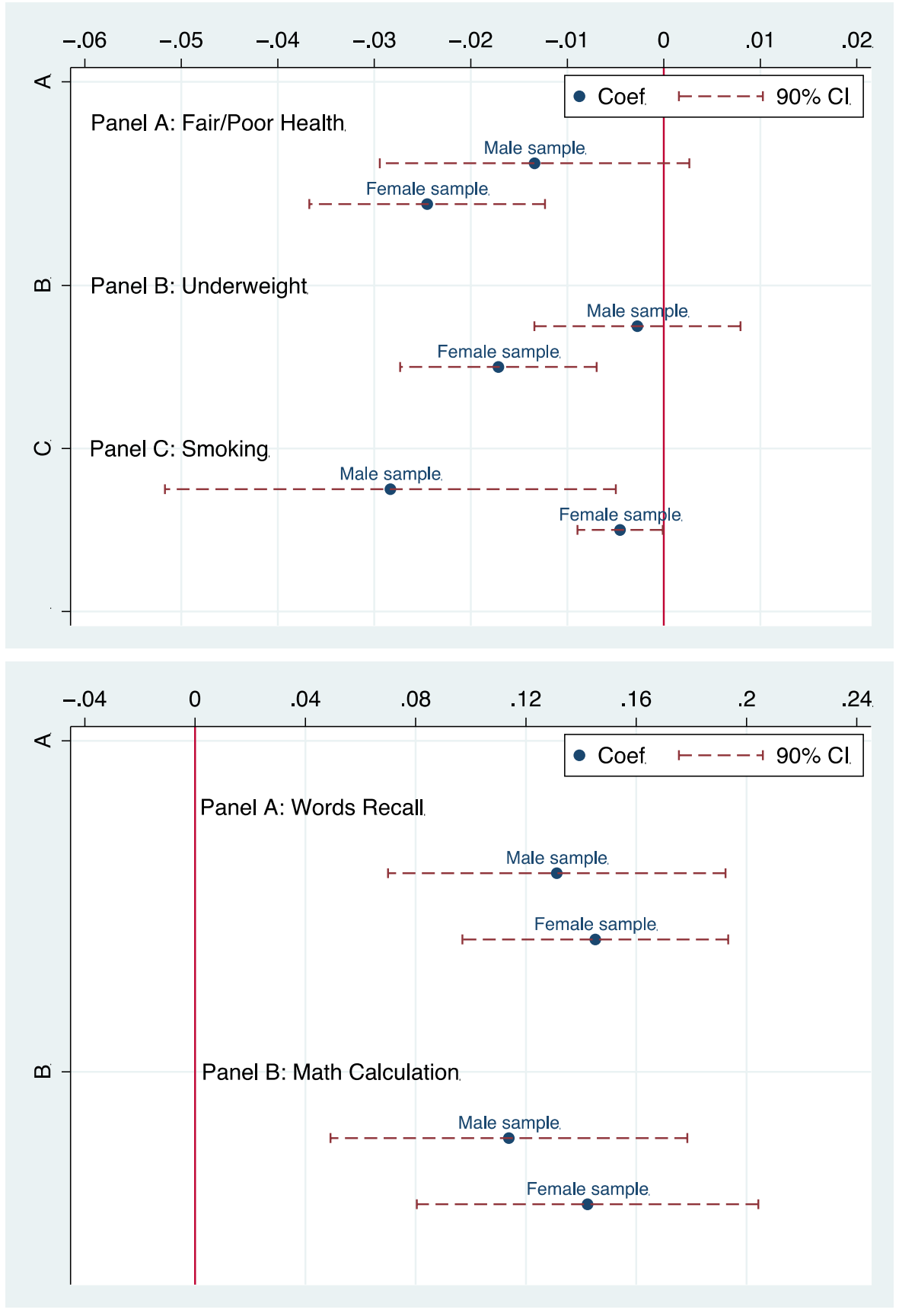

Figure 4a and 4b. Effects of Education on Health, by Gender

Notes: Data source is CFPS, CHIPs and CHNS. Gender-specific 2SLS estimation (Equation 2) is conducted for each outcome. The points show the coefficients on the years of schooling in the 2SLS estimation and the intervals are the 90\% confidential intervals based on standard errors clustered at province-year of birth level. 


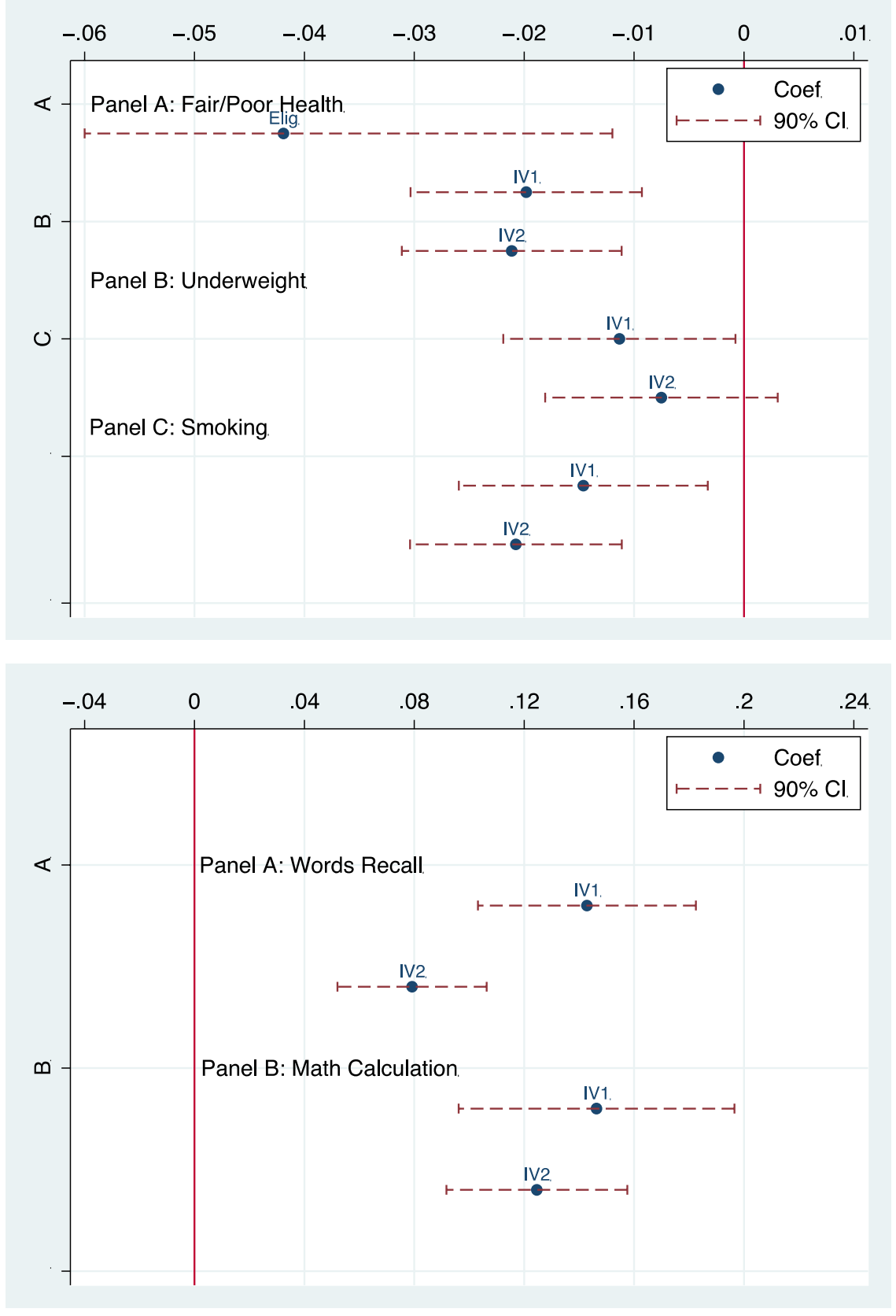

Figure 5a and 5b. Effects of Education on Health, by Different instruments

Notes: Data source is CFPS, CHIPs and CHNS. Two-Stage Least Squares estimation (Equation 4) is conducted for each outcome using two sets of different instruments. IV1: Eligible $_{i j}$ and prop $_{j}^{\text {prior }<9} \times$ Eligible $_{i j}$; IV2: Eligible $_{i j}$, prop $_{j}^{\text {prior }<9} \times$ Eligible $_{i j}$ and prop $_{j}^{\text {prior }<9}$ square $^{\text {. }} \times$ Eligible $_{i j}$. 


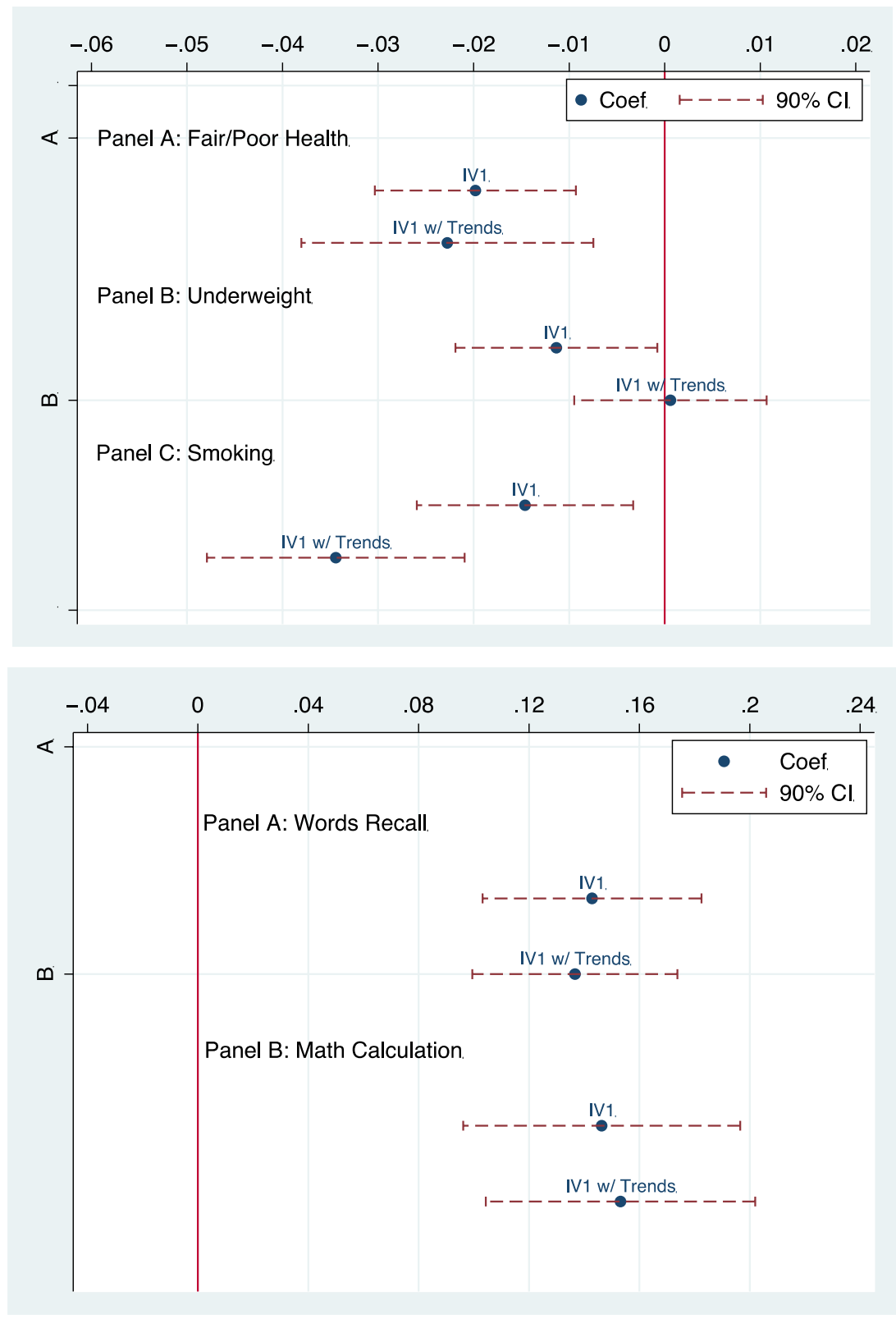

Figure 6a and 6b. Effects of Education on Health, with Provincial linear trends or not

Notes: Data source is CFPS, CHIPs and CHNS. Two-Stage Least Squares estimation (Equation 4) is conducted the different settings. The results marked "IV1" are original 2SLS results using Eligible $_{i j}$ and prop ${ }_{j}^{\text {prior }<9} \times$ Eligible $_{i j}$ as instruments. The results with "w/ trends" are the 2SLS adding the provincial specific linear trends in birth cohorts. 

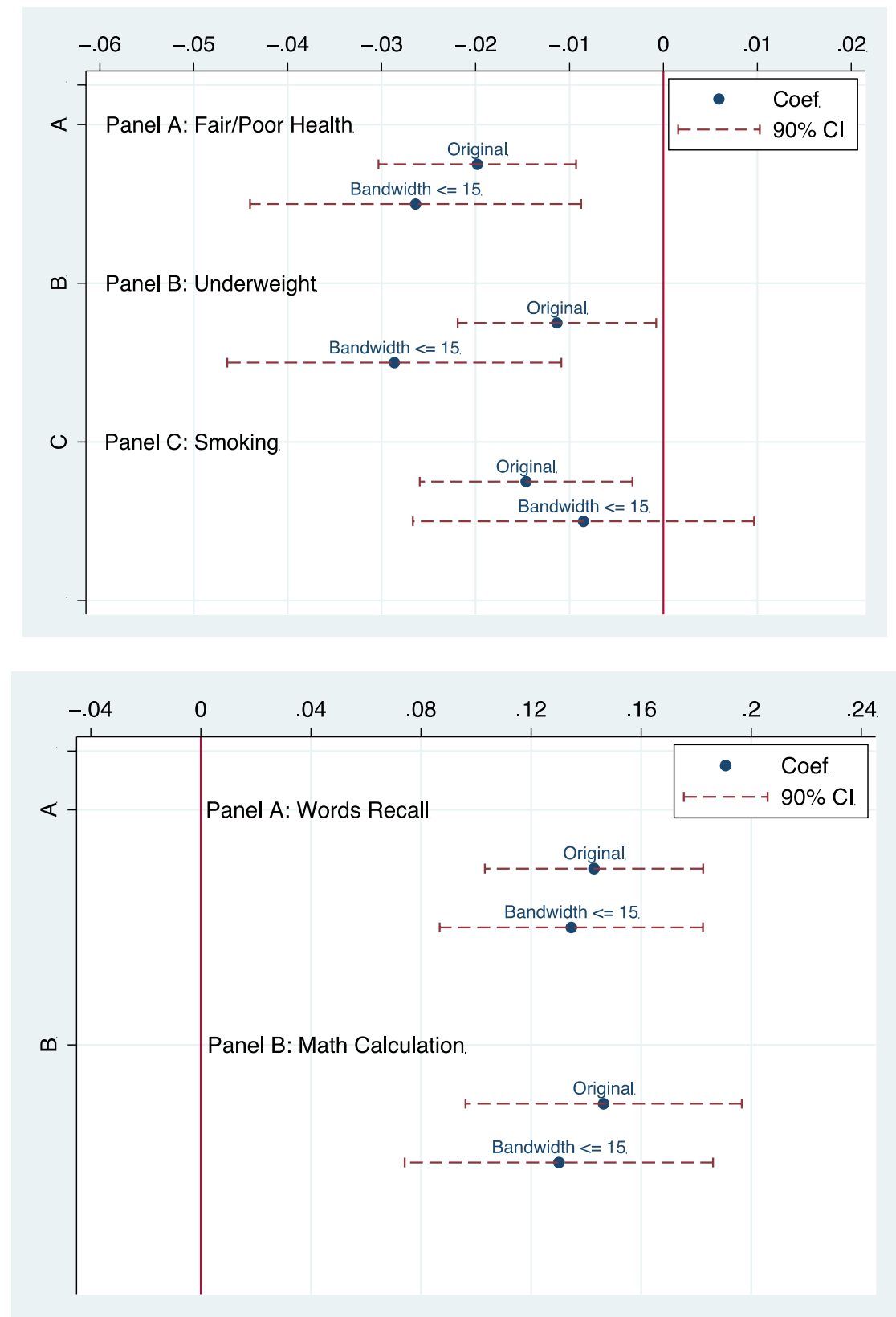

\section{Figure 7a and 7b. Effects of Education on Health, in Full and Trimmed samples}

Notes: Data source is CFPS, CHIPs and CHNS. Two-Stage Least Squares estimation (Equation 2) is conducted the different settings. The results marked "Original" are original 2SLS results using Eligible $i j$ and prop ${ }_{j}^{\text {prior }<9} \times$ Eligible $_{i j}$ as instruments. The results with "Bandwidth $<=15$ " are the 2SLS estimates using the sample between the birth cohorts 15 years earlier and later than the cohort just affected. 
Table A1. Summary Statistics

\begin{tabular}{lccccc}
\hline \hline Variable & Obs & Mean & Std. Dev. & Min & Max \\
\hline Panel A: Health & & & & & \\
Health Fair or Poor & 88971 & 0.19 & 0.39 & 0 & 1 \\
Health Excellent & 88971 & 0.28 & 0.45 & 0 & 1 \\
BMI & 85275 & 22.47 & 3.18 & 12.11 & 50 \\
Underweight & 85275 & 0.08 & 0.27 & 0 & 1 \\
Obese & 85275 & 0.02 & 0.15 & 0 & 1 \\
Smoke & 105634 & 0.26 & 0.44 & 0 & 1 \\
Panel B: Education and Demographics & & & & \\
Years of schooling & 114647 & 8.86 & 3.91 & 0 & 23 \\
Male & 114647 & 0.50 & 0.50 & 0 & 1 \\
Age & 114647 & 32.46 & 9.16 & 18 & 50 \\
Urban & 114647 & 0.39 & 0.49 & 0 & 1 \\
Married & 114647 & 0.54 & 0.55 & 0 & 9 \\
\hline \hline
\end{tabular}

Notes: Data source is CFPS, CHIPs and CHNS. 
Table A2. Compulsory Schooling Laws in different provinces

\begin{tabular}{|c|c|c|c|}
\hline Province & Law effect year & $\begin{array}{l}\text { First affected } \\
\text { birth cohort }\end{array}$ & $\begin{array}{c}\text { Prop of earlier cohorts } \\
\text { fewer than } 9 \text { years of } \\
\text { education }\end{array}$ \\
\hline Beijing & 1986 & 1971 & 0.053 \\
\hline Tianjin & 1987 & 1972 & 0.285 \\
\hline Hebei & 1986 & 1971 & 0.401 \\
\hline Shanxi & 1986 & 1971 & 0.394 \\
\hline Liaoning & 1986 & 1971 & 0.352 \\
\hline Jilin & 1987 & 1972 & 0.487 \\
\hline Heilongjiang & 1986 & 1971 & 0.385 \\
\hline Shanghai & 1987 & 1972 & 0.220 \\
\hline Jiangsu & 1987 & 1972 & 0.306 \\
\hline Zhejiang & 1986 & 1971 & 0.249 \\
\hline Anhui & 1987 & 1972 & 0.302 \\
\hline Fujian & 1989 & 1974 & 0.790 \\
\hline Jiangxi & 1986 & 1971 & 0.672 \\
\hline Shandong & 1987 & 1972 & 0.392 \\
\hline Henan & 1987 & 1972 & 0.358 \\
\hline Hubei & 1987 & 1972 & 0.288 \\
\hline Hunan & 1991 & 1976 & 0.357 \\
\hline Guangdong & 1987 & 1972 & 0.382 \\
\hline Guangxi & 1991 & 1976 & 0.381 \\
\hline Chongqing & 1986 & 1971 & 0.226 \\
\hline Sichuan & 1986 & 1971 & 0.318 \\
\hline Guizhou & 1988 & 1973 & 0.475 \\
\hline Yunnan & 1987 & 1972 & 0.499 \\
\hline Shaanxi & 1988 & 1973 & 0.409 \\
\hline Gansu & 1991 & 1976 & 0.577 \\
\hline Xinjiang & 1988 & 1973 & 0.581 \\
\hline
\end{tabular}

Notes: Data source is the education year books for each province. 
Table A3. OLS Estimation for Impact of CSLs on Years of Schooling

\begin{tabular}{|c|c|c|c|c|}
\hline \multirow{4}{*}{ Sample } & (1) & $(2)$ & $(3)$ & (4) \\
\hline & \multicolumn{4}{|c|}{ Dependent variable is Years of Schooling } \\
\hline & \multicolumn{2}{|c|}{ Subsamples by gender } & \multicolumn{2}{|c|}{ Subsamples by Type of Hukou } \\
\hline & Male & Female & Urban & Rural \\
\hline CSLs Eligibility & $\begin{array}{c}0.910 * * \\
(0.416)\end{array}$ & $\begin{array}{c}1.229 * * * \\
(0.469)\end{array}$ & $\begin{array}{c}0.233 \\
(0.496)\end{array}$ & $\begin{array}{c}1.576 * * * \\
(0.338)\end{array}$ \\
\hline $\operatorname{Pr}($ less than 9-year education) $*$ & $3.173 * * *$ & $4.765 * * *$ & $1.982 * *$ & $4.499 * * *$ \\
\hline Eligibility & $(0.699)$ & $(0.769)$ & $(0.777)$ & $(0.644)$ \\
\hline Observations & 56,832 & 57,815 & 45,264 & 69,383 \\
\hline R-squared & 0.201 & 0.288 & 0.200 & 0.275 \\
\hline F-statistic for all the variables & 12.41 & 21.67 & 3.272 & 35.70 \\
\hline $\mathrm{P}$-value for the F-test & $4.45 \mathrm{e}-06$ & $4.96 \mathrm{e}-10$ & 0.0382 & 0 \\
\hline
\end{tabular}

Notes: Data source is CFPS, CHIPs and CHNS. Robust standard errors in parentheses are clustered at province-year of birth level. Covariates are the same with Table 1. 
Table A4. Impact of Education on Health is Larger for the lower education group

\begin{tabular}{|c|c|c|c|c|c|}
\hline VARIABLES & $\begin{array}{c}\text { (1) } \\
\text { Health Fair or } \\
\text { Poor (Yes =1) }\end{array}$ & $\begin{array}{c}(2) \\
\text { Underweight } \\
(\text { Yes }=1)\end{array}$ & $\begin{array}{c}(3) \\
\text { Smoker } \\
(\text { Yes = 1) }\end{array}$ & $\begin{array}{c}4) \\
\text { Words recall Z- } \\
\text { score }\end{array}$ & $\begin{array}{c}\text { (5) } \\
\text { Math Ability Z- } \\
\text { Score }\end{array}$ \\
\hline \multicolumn{6}{|c|}{ Panel A: Years of Schooling $<=9$ Sample } \\
\hline Years of Schooling & $\begin{array}{c}-0.0103 * * * \\
(0.000711)\end{array}$ & $\begin{array}{c}-0.00173 * * * \\
(0.000446)\end{array}$ & $\begin{array}{l}-0.000449 \\
(0.000619)\end{array}$ & $\begin{array}{l}0.111 * * * \\
(0.00201)\end{array}$ & $\begin{array}{l}0.140 * * * \\
(0.00163)\end{array}$ \\
\hline Observations & 57,933 & 55,921 & 70,123 & 25,665 & 19,820 \\
\hline R-squared & 0.114 & 0.048 & 0.413 & 0.302 & 0.418 \\
\hline \multicolumn{6}{|c|}{ Panel B: Years of Schooling > 9 Sample } \\
\hline Years of Schooling & $\begin{array}{c}-0.00347 * * \\
(0.00150)\end{array}$ & $\begin{array}{c}0.0000 \\
(0.00120)\end{array}$ & $\begin{array}{c}-0.0151 * * * \\
(0.00168)\end{array}$ & $\begin{array}{c}0.0593 * * * \\
(0.00432)\end{array}$ & $\begin{array}{c}0.0831 * * * \\
(0.00491)\end{array}$ \\
\hline Observations & 31,038 & 29,354 & 35,511 & 9,334 & 8,372 \\
\hline R-squared & 0.074 & 0.084 & 0.321 & 0.172 & 0.362 \\
\hline
\end{tabular}

Notes: Data source is CFPS, CHIPs and CHNS. The sample is divided by years of education. Robust standard errors in parentheses are clustered at province-year of birth level. Covariates are the same with Table 1. 
Table A5. Impact of Education on Health, Robustness Checks

\begin{tabular}{lccc}
\hline \hline Setting & $(1)$ & $\begin{array}{c}(2) \\
\text { Drop CHNS } \\
\text { sample }\end{array}$ & Health Excellent \\
\hline VARIABLES & $\begin{array}{c}\text { Health Fair or } \\
\text { Poor (Yes }=1)\end{array}$ & $\begin{array}{c}\text { Health Fair or } \\
\text { Poor }(\text { Yes }=1)\end{array}$ & $\begin{array}{c}\text { Health Excellent } \\
(\text { Yes }=1)\end{array}$ \\
\hline Years of Schooling & $-0.0204 * * *$ & $-0.0215^{* * *}$ & $0.0123^{*}$ \\
& $(0.00643)$ & $(0.00630)$ & $(0.00681)$ \\
Observations & & & 88,971 \\
F & 88,971 & 69,042 & 27.24 \\
Hansen & 27.24 & 33.54 & 0.00207 \\
Hansen-P & 2.285 & 0.208 & 0.964 \\
\hline \hline
\end{tabular}

Notes: Data source is CFPS, CHIPs and CHNS. Robust standard errors in parentheses are clustered at province-year of birth level. Covariates are the same with Table 1. 
Table A6. Impact of Education on BMI Related Variables, Robustness Checks

\begin{tabular}{lccccc}
\hline \hline Setting & $\begin{array}{c}(1) \\
\text { Original }\end{array}$ & $\begin{array}{c}(2) \\
\text { Use Obese }\end{array}$ & $\begin{array}{c}(3) \\
\text { BMI in the } \\
\text { full sample }\end{array}$ & $\begin{array}{c}(4) \\
\text { BMI }<22 \\
\text { sample }\end{array}$ & $\begin{array}{c}\text { BMI }>=22 \\
\text { sample }\end{array}$ \\
\hline VARIABLES & $\begin{array}{c}\text { Underweight } \\
(\text { Yes }=1)\end{array}$ & $\begin{array}{c}\text { Obese } \\
(\text { Yes }=1)\end{array}$ & BMI & BMI & BMI \\
\hline Years of Schooling & $-0.0118^{*}$ & 0.00112 & $0.132^{* *}$ & $0.0615^{* *}$ & -0.0591 \\
& $(0.00626)$ & $(0.00235)$ & $(0.0634)$ & $(0.0279)$ & $(0.144)$ \\
Observations & & & & & \\
F & 85,275 & 85,275 & 85,275 & 41,246 & 44,029 \\
Hansen & 28.09 & 28.09 & 28.09 & 45.91 & 5.725 \\
Hansen-P & 1.235 & 0.747 & 3.227 & 1.519 & 3.453 \\
\hline \hline
\end{tabular}

Notes: Data source is CFPS, CHIPs and CHNS. Robust standard errors in parentheses are clustered at province-year of birth level. Covariates are the same with Table 1. 
Table A7. Impact of Education on Health, Health Behaviors and Cognition, Robustness checks

\begin{tabular}{|c|c|c|c|c|c|}
\hline VARIABLES & $\begin{array}{c}(1) \\
\text { Health Fair or } \\
\text { Poor (Yes = 1) }\end{array}$ & $\begin{array}{c}(2) \\
\text { Underweight } \\
(\text { Yes = 1) }\end{array}$ & $\begin{array}{c}(3) \\
\text { Smoker } \\
(\text { Yes = 1) }\end{array}$ & $\begin{array}{c}\text { (4) } \\
\text { Words recall Z- } \\
\text { score }\end{array}$ & $\begin{array}{c}\text { (5) } \\
\text { Math Ability Z- } \\
\text { Score }\end{array}$ \\
\hline \multicolumn{6}{|c|}{ Panel A. 2SLS Results with weights } \\
\hline Years of Schooling & $\begin{array}{c}-0.0171 * * * \\
(0.00583)\end{array}$ & $\begin{array}{c}-0.0137 * * \\
(0.00533)\end{array}$ & $\begin{array}{l}-0.00830 \\
(0.00648)\end{array}$ & $\begin{array}{c}0.139 * * * \\
(0.0222)\end{array}$ & $\begin{array}{c}0.166 * * * \\
(0.0263)\end{array}$ \\
\hline Observations & 88,971 & 85,275 & 105,634 & 34,999 & 28,192 \\
\hline F-Statistics for IV(s) in 1st stage & 36.06 & 43.22 & 38.69 & 15.61 & 12.81 \\
\hline P-values for IV F-tests & 0.000 & 0.000 & 0.000 & 0.000 & 0.000 \\
\hline \multicolumn{6}{|c|}{ Panel B. 2SLS using completing junior high school as the key independent variable } \\
\hline Junior High completion (Yes =1) & $\begin{array}{c}-0.187 * * * \\
(0.0647)\end{array}$ & $\begin{array}{c}-0.146 * * * \\
(0.0528)\end{array}$ & $\begin{array}{c}-0.0838 \\
(0.0721)\end{array}$ & $\begin{array}{c}1.460 * * * \\
(0.274)\end{array}$ & $\begin{array}{c}1.403 * * * \\
(0.318)\end{array}$ \\
\hline Observations & 88,971 & 85,275 & 105,634 & 34,999 & 28,192 \\
\hline F-Statistics for IV(s) in 1st stage & 32.21 & 50.32 & 32.71 & 17.80 & 16.62 \\
\hline P-values for IV F-tests & 0.000 & 0.000 & 0.000 & 0.000 & 0.000 \\
\hline
\end{tabular}

Notes: Data source is CFPS, CHIPs and CHNS. Robust standard errors in parentheses are clustered at province-year of birth level. Covariates are the same with Table 1. Panel A weights the regression by the population of the province divided by the number of observations. Panel B uses the indicator of completing junior high school as the main independent variable and conducts the 2SLS estimation. 
Table A8. Channel Analysis, Robustness checks

\begin{tabular}{|c|c|c|c|c|c|c|c|c|c|c|}
\hline \multirow{3}{*}{$\begin{array}{l}\text { VARIABLES } \\
\text { Channel examined }\end{array}$} & (1) & (2) & (3) & (4) & $(5)$ & $(6)$ & (7) & $(8)$ & $(9)$ & (10) \\
\hline & \multicolumn{10}{|c|}{ Health Fair or Poor $($ Yes $=1)$} \\
\hline & \multicolumn{2}{|c|}{ BMI } & \multicolumn{2}{|c|}{ Smoking } & \multicolumn{2}{|c|}{ Income } & \multicolumn{2}{|c|}{ Cognition } & \multicolumn{2}{|c|}{ Peer effects } \\
\hline Settings & Basic & $\begin{array}{c}\text { Basic }+ \\
\text { Channel } \\
\end{array}$ & Basic & $\begin{array}{c}\text { Basic }+ \\
\text { Channel }\end{array}$ & Basic & $\begin{array}{c}\text { Basic }+ \\
\text { Channel } \\
\end{array}$ & Basic & $\begin{array}{c}\text { Basic + } \\
\text { Channel }\end{array}$ & Basic & $\begin{array}{c}\text { Basic }+ \\
\text { Channel } \\
\end{array}$ \\
\hline $\begin{array}{l}\text { Part of impact can be } \\
\text { explained }\end{array}$ & & $12.6 \%$ & & $0.3 \%$ & & $22.1 \%$ & & $12.6 \%$ & & $9.9 \%$ \\
\hline CSLs Eligibility & $\begin{array}{c}-0.0606 * * * \\
(0.0217)\end{array}$ & $\begin{array}{c}-0.0596 * * * \\
(0.0218)\end{array}$ & $\begin{array}{l}-0.0383 * \\
(0.0223)\end{array}$ & $\begin{array}{l}-0.0387 * \\
(0.0223)\end{array}$ & $\begin{array}{c}-0.0606 * * * \\
(0.0217)\end{array}$ & $\begin{array}{c}-0.0589 * * * \\
(0.0214)\end{array}$ & $\begin{array}{l}-0.0584 * \\
(0.0323)\end{array}$ & $\begin{array}{l}-0.0464 \\
(0.0324)\end{array}$ & $\begin{array}{c}-0.0606 * * * \\
(0.0217)\end{array}$ & $\begin{array}{c}-0.0617 * * * \\
(0.0216)\end{array}$ \\
\hline $\begin{array}{l}\text { Pr(less than 9-year } \\
\text { education) * Eligibility }\end{array}$ & $\begin{array}{c}-0.0747 * * \\
(0.0324)\end{array}$ & $\begin{array}{c}-0.0653 * * \\
(0.0326)\end{array}$ & $\begin{array}{r}-0.0464 \\
(0.0340)\end{array}$ & $\begin{array}{l}-0.0463 \\
(0.0340)\end{array}$ & $\begin{array}{c}-0.0747 * * \\
(0.0324)\end{array}$ & $\begin{array}{l}-0.0582 * \\
(0.0323)\end{array}$ & $\begin{array}{c}-0.0908 * * \\
(0.0383)\end{array}$ & $\begin{array}{c}-0.0794 * * \\
(0.0380)\end{array}$ & $\begin{array}{c}-0.0747 * * \\
(0.0324)\end{array}$ & $\begin{array}{l}-0.0674 * \\
(0.0369)\end{array}$ \\
\hline Observations & 88,968 & 88,968 & 81,602 & 81,602 & 88,968 & 88,968 & 35,049 & 35,049 & 88,968 & 88,968 \\
\hline R-squared & 0.092 & 0.095 & 0.099 & 0.099 & 0.092 & 0.098 & 0.121 & 0.128 & 0.092 & 0.092 \\
\hline
\end{tabular}

Notes: Data source is CFPS, CHIPs and CHNS. Robust standard errors in parentheses are clustered at province-year of birth level. Covariates are the same with Table 1. 


\section{Data Appendix}

\section{China Health and Nutrition Survey (CHNS)}

The China Health and Nutrition Survey (CHNS), an ongoing open cohort, international collaborative project between the Carolina Population Center at the University of North Carolina at Chapel Hill and the National Institute of Nutrition and Food Safety at the Chinese Center for Disease Control and Prevention, was designed to examine the effects of the health, nutrition, and family planning policies and programs implemented by national and local governments and to see how the social and economic transformation of Chinese society is affecting the health and nutritional status of its population. The impact on nutrition and health behaviors and outcomes is gauged by changes in community organizations and programs as well as by changes in sets of household and individual economic, demographic, and social factors. The survey was conducted by an international team of researchers whose backgrounds include nutrition, public health, economics, sociology, Chinese studies, and demography. The survey took place over a 3-day period using a multistage, random cluster process to draw a sample of about 4400 households with a total of 26,000 individuals in nine provinces that vary substantially in geography, economic development, public resources, and health indicators. In addition, detailed community data were collected in surveys of food markets, health facilities, family planning officials, and other social services and community leaders.

The CHNS data collection began in 1989 and has been implemented every 2e4 years since. The CHNS uses a multistage cluster sample design to survey individuals and households within 218 neighborhoods within nine provinces in China. These nine provinces contain approximately $56 \%$ of the population of China. To obtain the sample from these nine provinces, the counties inside the provinces were stratified by income then a weighted sample of four counties was selected, as was the provincial capital city and a lower-income city in each province. Within these cities or counties, neighborhoods were randomly selected, resulting, originally, in 190 communities and, currently, in 218 communities. The mean (standard deviation) number of 
households per community was 21 (2.1). Households were selected randomly from a community household roster and all members in each household were interviewed. The household roster was used to follow-up each of the originally sampled households as well as new households formed from previous households for subsequent survey panels. The baseline sample was representative of each province but over time, loss-to-follow-up has occurred. Overall, $85 \%$ of households have been surveyed in at least five of seven rounds (Barry M. Popkin, Du, Zhai, \& Zhang, 2009).

The CHNS includes individual, household, and community-level surveys conducted by trained field worker; the current analysis utilizes information from each of these surveys. The household and individual surveys were conducted inside the participant's home. The community survey obtained detailed information on the community infrastructure, services, and demographic/economic environment from a combination of neighborhood officials, informants, visits to markets, and official records (Monda et al., 2007). Ethical approval was provided by the Internal Review Board of University of North Carolina at Chapel Hill and Chinese Center for Disease Control.

\section{Chinese Family Panel Studies (CFPS)}

The Chinese Family Panel Studies (CFPS) is by far the largest and latest comprehensive household survey with information on demographic, economic, and health aspects of households in China. It is a biennial survey and is designed to be complementary to the Panel Study of Income Dynamics (PSID) in the United States. The first national wave was conducted under the collaboration of the Institute of Social Science Survey at Peking University and the Survey Research Center at the University of Michigan from April 2010 to August 2010. The five main parts of the questionnaire include communities, households, household members, adults and children data.

The 2010 round covered approximately 14,000 households in 25 provinces, in which $95 \%$ of 
the Chinese population reside. ${ }^{1}$ The population is divided into six subpopulation, i.e. five large provinces (Guangdong, Gansu, Liaoning, Henan, Shanghai) and the other 20 provinces. The final sample is made to be representative of 25 provinces through careful weighting.

The sample was obtained by three-stage cluster sampling with unequal probabilities. In the first stage, 16 counties were sampled from each of the four large provinces, ${ }^{2}$ and 80 counties from 20 other provinces, with probability proportional to population (pps). In total there were 144 counties. In the second stage, 2 or 4 administrative villages or resident committees were sampled with pps in each county or town. Together there were 664 villages or resident committees. In the third stage, 28-42 households were sampled from each village or resident committee, and in all there were about 14,000 households. The national representative final sample covers about 9,500 households and 21,760 adults.

\section{Chinese Household Income Project Series (CHIPS)}

The purpose of the Chinese Household Income Project was to measure and estimate the distribution of personal income in both rural and urban areas of the People's Republic of China. The principal investigators based their definition of income on cash payments and on a broad range of additional components: payments in kind valued at market prices, agricultural output produced for self-consumption valued at market prices, the value of ration coupons and other direct subsidies, and the imputed value of housing. Data were collected through a series of questionnaire-based interviews conducted in rural and urban areas in 1988, 1995, 2002 and 2007. Individual respondents reported on their economic status, employment, level of education, sources of income, household composition, and household expenditures.

The study was interview-based. Five main questionnaire forms (Urban, Rural, Rural Migrant, Social Network, and Village) were filled in by interviewers at the various locations, based on

\footnotetext{
${ }^{1}$ Hainan, Inner Mongolia, Ningxia, Qinghai, Tibet, Xinjiang, and Hong Kong, Macau, Taiwan are not excluded from the survey.

2 Shanghai excluded. 32 neighborhoods or towns were sampled from Shanghai using pps.
} 
questions asked of respondents. Individuals were not all interviewed directly; household members were allowed to answer questions on behalf of other members. In addition, interviewers made some direct observations about the households. Respondents in datasets 1-4 and 6-10 were members and heads of households. In dataset 5, respondents were village representatives: for each village, interviewers asked questions of the party branch secretary, the head of the village committee, or the village accountant. Village authorities were encouraged to use existing statistical data where it was available.

For each year, there are three different datasets for urban, rural residents and migrants, separately. This study only uses the data for the residents. On average, each year has over 20,000 individuals in urban or rural survey. ${ }^{3}$ The data are coded on-site observation through face-to-face interview

\section{Additional References}

Jones-Smith, Jessica C., and Barry M. Popkin. "Understanding community context and adult health changes in China: development of an urbanicity scale." Social science \& medicine 71.8 (2010): 1436-1446.

Monda, Keri L., et al. "China's transition: the effect of rapid urbanization on adult occupational physical activity." Social science \& medicine 64.4 (2007): 858-870.

Popkin, Barry M., Richard E. Bilsborrow, and John S. Akin. "Breast-feeding patterns in low-income countries." Science 218.4577 (1982): 1088-1093.

Griffin, Keith, and Zhao Renwei. "Chinese Household Income Project, 1988." (1993).

Shi, Li. "Chinese household income project, 2002." (2008).

3 (http://www.icpsr.umich.edu/icpsrweb/ICPSR/series/243) 